\title{
Liquorveränderungen bei Meningeosis neoplastica - eine retrospektive Studie (2001-2012) -
}

\author{
INAUGURAL-DISSERTATION \\ zur Erlangung des Doktorgrades \\ der Medizinischen Fakultät der \\ Georg-August-Universität zu Göttingen \\ vorgelegt von \\ Ralf Christian Gerhard Trimmel
}

aus

Bremen

Göttingen 2017 
Dekan:

Referent/in:

Ko-Referent/in:

Drittreferent/in:
Prof. Dr. rer. nat. H. K. Kroemer

PD. Dr. med. Marija Djukic

Prof. Dr. Inga Zerr

Prof. Dr. Margarete Schön

Datum der mündlichen Prüfung: 02.05.2018 
Hiermit erkläre ich, die Dissertation mit dem Titel "Liquorveränderungen bei Meningeosis neoplastica - eine retrospektive Studie (2001-2012)" eigenständig angefertigt und keine anderen als die von mir angegebenen Quellen und Hilfsmittel verwendet zu haben.

Göttingen, den

(Unterschrift) 
Die Inhalte der vorliegenden Arbeit wurden publiziert:

Djukic M, Trimmel R, Nagel I, Spreer A, Lange P, Stadelmann C, Nau R (2017):

Cerebrospinal fluid abnormalities in meningeosis neoplastica: a retrospective 12-years analysis. Fluids Barriers CNS $\underline{14}$, 1-7 


\section{Inhaltsverzeichnis}

Inhaltsverzeichnis...................................................................

Abkürzungsverzeichnis....................................................................................

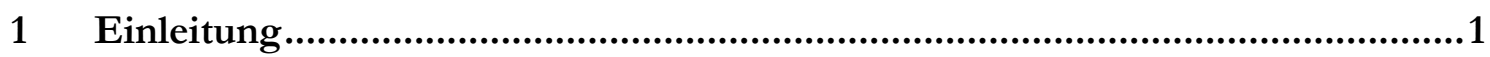

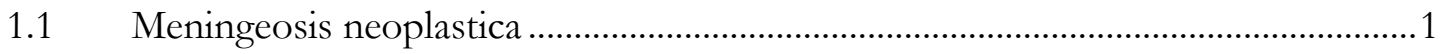

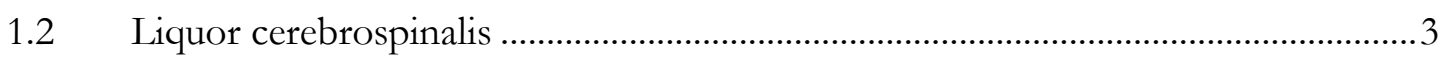

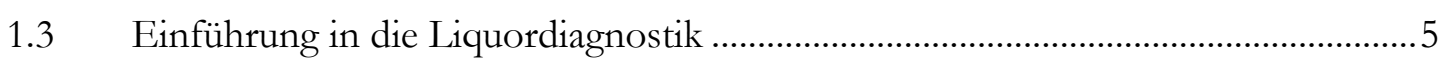

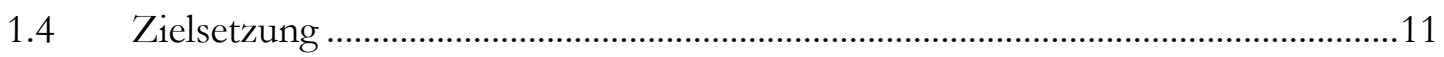

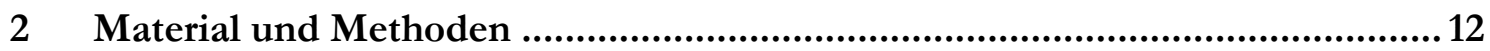

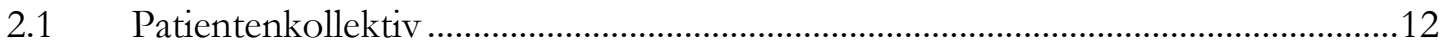

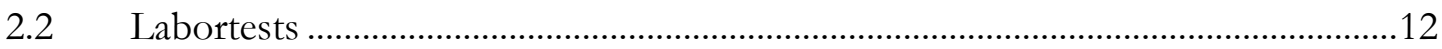

2.2.1 Fuchs-Rosenthal-Zählkammer und Zelldifferenzierung.........................................12

2.2.2 May-Grünwald-Giemsa-Färbung .............................................................................13

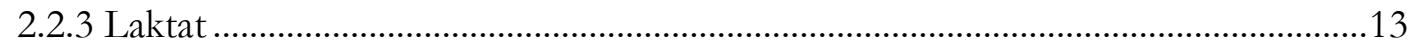

2.2.4 Gesamtprotein ..........................................................................................................

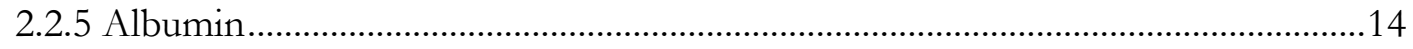

2.2.6 IgG, IgA und IgM im Liquor und im Serum ...................................................14

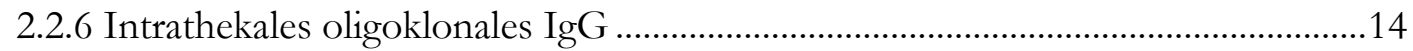

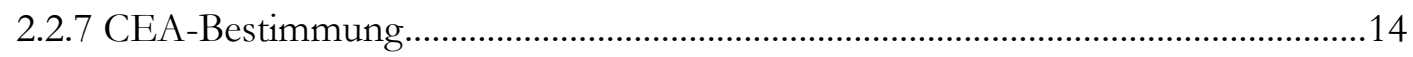

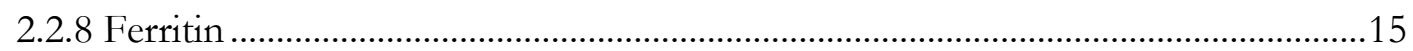

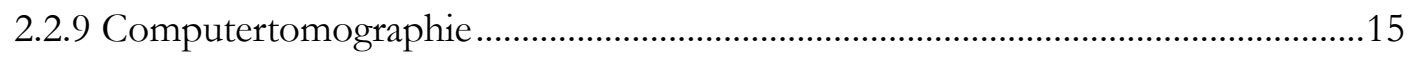

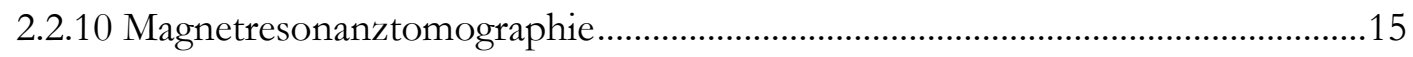

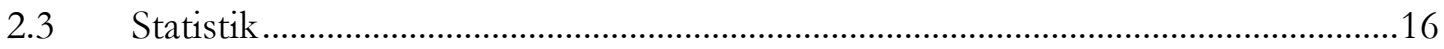

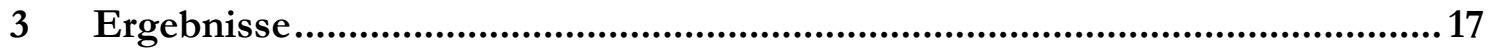

3.1 Vorerkrankungen und Symptome bei Aufnahme ………........................................18

3.2 Liquorveränderungen bei der Meningeosis neoplastica............................................22

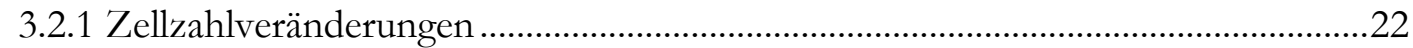

3.2.2 Laktatveränderungen im Liquor ..........................................................................22

3.2.3 Gesamtprotein/ Schrankenstörungen .........................................................................23

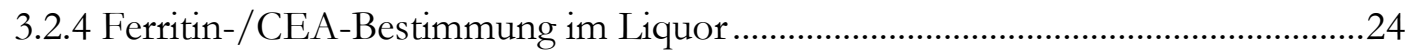

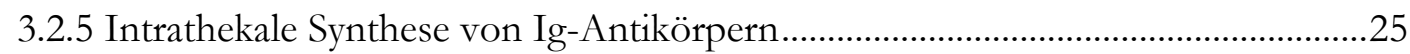




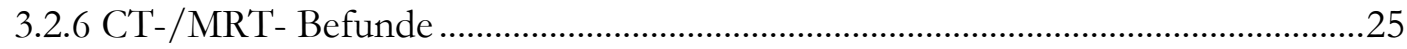

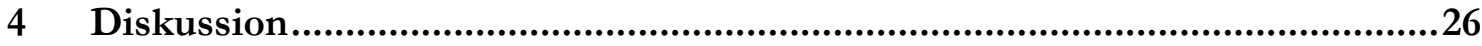

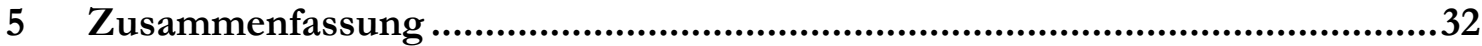

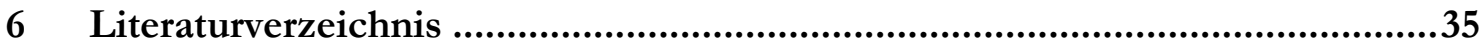

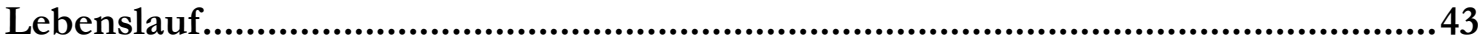




\section{Abkürzungsverzeichnis}

$\begin{array}{ll}\text { AFP } & \text { alpha-Fetoprotein } \\ \text { ca. } & \text { Circa } \\ \text { CEA } & \text { carcinomembryonales Antigen } \\ \text { CT } & \text { Computertomographie } \\ \text { CYFRA21-1 } & \text { Cytokeratinfragment 21-1 } \\ \text { DGLN } & \text { Deutsche Gesellschaft für Liquordiagnostik und Klinische Neuro- } \\ & \text { chemie } \\ \text { DGN } & \text { Deutsche Gesellschaft für Neurologie } \\ \text { E.coli } & \text { Escherichia coli } \\ \text { ELISA } & \text { Enzyme-linked Immunosorbent Assay } \\ \text { et al. } & \text { et alii } \\ \text { ggf. } & \text { gegebenenfalls } \\ \text { HCG } & \text { humanes Choriongonadotropin } \\ \text { HSV } & \text { Herpes-simplex-Virus } \\ \text { IgA } & \text { Immunglobulin A } \\ \text { IgG } & \text { Immunglobulin G } \\ \text { IgM } & \text { Immunglobulin M } \\ \text { LWK } & \text { Lendenwirbelkörper } \\ \text { LWS } & \text { Lendenwirbelsäule } \\ \text { MRT } & \text { Magnetresonanztomographie } \\ \text { N. meningitidis } & \text { Neisseria meningitides } \\ \text { NSE } & \text { neuronenspezifische Enolase } \\ \text { o. Verl. } & \text { ohne Verlag } \\ \text { rS } & \text { Spearman's Rangkorrelationkoeffizient } \\ \text { SD } & \text { Standardabweichung } \\ \text { TCA } & \text { Trichloressigsäure } \\ \text { z.B. } & \text { zum Beispiel } \\ \text { ZNS } & \text { Zentrales Nervensystem } \\ \end{array}$




\section{$1 \quad$ Einleitung}

\subsection{Meningeosis neoplastica}

Die Meningeosis neoplastica ist eine meningeale Karzinose und Ausdruck der systemischen Disseminierung eines Tumorleidens, die Karl Joseph Eberth, ein deutscher Pathologe, 1870 erstmals beschrieb (Eberth 1870).

Die Meningeosis neoplastica beschreibt im Allgemeinen die Infiltration der Meningen durch Malignitäten, dazu gehören u. a. die Meningeosis carcinomatosa und Meningeosis lymphomatosa sowie die Aussaat primärer Tumoren des zentralen Nervensystems, wie z. B. Germinome, Medullablastome, neuroektodermale Tumoren, Ependymome und bösartige Gliome. Pathogenetisch kommt es zu einer hämatogenen Einwanderung der Tumorzellen über die arterielle und venöse Versorgung des Gehirns (Rosen et al. 1982) mit einer diffusen metastatischen Ausbreitung von Tumorzellen im Subarachnoidalraum oder per continuitatem aus knöchernen Metastasen der Kalotte und Wirbelsäule (DGN 2014). Nach dem Eindringen der malignen Zellen in den Liquor breiten sich diese dann entlang der meningealen Oberfläche aus oder wandern durch den Liquorfluss in das gesamte Zentralnervensystem. Besonders die abgelösten Zellen verbleiben an Orten, an denen es zu einer Stase des Liquors kommt, also im Bereich der basalen Zisternen, der Cauda equina oder des Sulcus hippocampi (Grossman und Krabak 1999).

Durch den Befall der Virchow-Robin-Räume kann es durch diese Infiltration der Hirn- und Rückenmark versorgenden Gefäße zu perivaskulären Einengungen und Ischämien kommen. Ablagerungen von Tumorzellen im Bereich des Aquaeductus mesencephali, des Ventrikelsystems, der basalen Zisternen oder im Subarachnoidalraum können zu einer Störung der Liquorzirkulation führen, wodurch es zu einem Anstieg des intrakraniellen Druckes und in dessen Folge zu einem Hydrozephalus kommen kann (Pentheroudakis und Pavlides 2005).

Die Häufigkeit der Meningeosis neoplastica bei malignen Erkrankungen liegt im Verlauf bei etwa 5-10\% (Bruna et al. 2009).

Am häufigsten tritt sie in der Folge eines Mamma- (ca. 25 - 50\%) oder Bronchialkarzinoms (ca. 20\% - 35\%) auf, aber auch bei malignen Melanomen, Lymphomen und Leukämien kann die Meningeosis neoplastica gefunden werden (Kaplan et al. 1990, Herrlinger et al. 2004). Eine meningeale Aussaat bei gastrointestinalen und Urogenitalkarzinomen ist selten (ca. 5\%). Die Meningeosis neoplastica kommt auch bei primären Hirntumoren vor (weniger als 2\%), 
insbesondere Germinomen, Medulloblastomen und primitiven neurektodermalen Tumoren (Chamberlain 1997).

Klinisch klagen die Patienten vor allem über Wesensveränderung, Kopfschmerzen, Übelkeit, Erbrechen, Paresen, radikuläre Schmerzen, Hirnnervenparesen sowie Mastdarm- und Blasenentleerungsstörungen (Wasserstrom et al. 1982, DGN 2014, Ohnoshi et al. 1993). Das klassische klinische Zeichen Meningismus ist bei ca. 20\% aller Betroffenen zu finden (Wasserstrom et al. 1982). Die mediane Überlebenszeit liegt ohne Behandlung bei 6-8 Wochen bei soliden Tumoren. Die Behandlung beinhaltet eine kombinierte Therapie aus Strahlen-, sowie medikamentöser Therapie. Als potenzielle negativ prognostische Faktoren für die Überlebenszeit sind ein niedriger Karnofsky-Index, Hirnnervenparesen, hohes Alter, niedrige Glukose und ein hohes Protein im Liquor identifiziert worden (Herrlinger et al. 2004, Chamberlain et al. 2005, Jaeckle 2006).

Um die Diagnose einer Meningeosis neoplastica stellen zu können, sind neben einer neurologischen und internistischen Untersuchung sowie Bildgebung der Neuroachse insbesondere die Liquoruntersuchung mit Druckmessung, Zellzahlbestimmung, LiquorZytologie (auch bei normaler Zellzahl) und Bestimmung von Albumin oder Gesamtprotein, IgG, Glukose und Laktat erforderlich (DGN 2014). Die definitive Diagnose einer Meningeosis neoplastica erfolgt durch den zytologischen Nachweis von Tumorzellen im Liquorsediment (DGN 2014) und die Zytologie besitzt qualitativ den höchsten Stellenwert. Der direkte Nachweis gelingt jedoch nur in 50\% der Fälle, sodass häufig erst nach zwei weiteren Punktionen die Tumorzellen bei ca. 90\% nachgewiesen werden können (Hau und Pukrop 2015). Bei ca. 5-10\% aller Betroffenen kann allerdings eine Diagnose aufgrund des fehlenden Nachweises von Tumorzellen nicht gestellt werden (Jaeckle 2006).

Neben dem Nachweis von Tumorzellen im Liquor ist eine Liquor-Proteinerhöhung, obwohl es ein unspezifischer Parameter ist, bei ca. 80-90\% aller Meningeosis-Patienten zu finden und stellt den sensitivsten Indikator für die Diagnose einer Meningeosis neoplastica dar (Glass et al. 1979).

Entzündliche Begleitreaktionen sind im Rahmen einer Meningeosis neoplastica möglich und können eine differentialdiagnostische Zuordnung des Liquorbefundes erschweren (Zettl et al. 2005). Eine Pleozytose (Zellzahlerhöhung $>4$ Leukozyten/ $\mu$ ) unterschiedlichen Ausmaßes kann in über 70\% der Meningeosis-Fälle gefunden werden (Zettl et al. 2005).

Ebenfalls ist die Erkrankung mit einer deutlichen Erhöhung des Liquorlaktats assoziiert (Wasserstrom et al. 1982). Dabei liegen die Werte des Liqourlaktats oft über Werten von 3,5 mmol/l. Aufgrund des Laktatanstiegs kommt es parallel zu einer Abnahme der 
Glukosekonzentration, die in bis zu 80\% der Fälle gefunden werden kann (Zettl et al. 2005). Bei weniger als 5\% kann ein vollkommen normaler Liquorbefund erhoben werden (Wasserstrom et al 1982).

\subsection{Liquor cerebrospinalis}

Die Rückenmarksflüssigkeit/Liquor cerebrospinalis ist eine klare Flüssigkeit, die vom französischen Mediziner, Anatom und Physiologen Francois Magendie entdeckt wurde. Der normale Liquor cerebrospinalis enthält kaum Zellen und erfüllt aufgrund seiner dynamischen und metabolischen Aktivität viele wichtige Aufgaben, u. a. die Ausfüllung der Ventrikel und des Subarachnoidalraums, der das Gehirn und Rückenmark umgibt und somit als eine Art Schutzschild für das empfindliche Hirnparenchym und das Rückenmark dient. Er fungiert somit als Puffer bei abrupten Kopfbewegungen (z. B. Aufprall des Schädels gegen eine harte Oberfläche) und schützt so das Gehirn vor Kontusionsverletzungen. Außerdem dient der Liquor als eine Art Lymphsystem und stellt die Versorgung des Gehirns mit Nährstoffen, wie z. B. Glukose, sicher und entsorgt anfallende Abbau-/Abfallprodukte. Man geht davon aus, dass peptiderge und andere Substanzen aktiv als Botenstoffe in den Liquor sezerniert und dort verteilt werden. Durch diese Verteilung gelangen diese an verschiedene Stellen des Gehirns und beeinflussen dort bestimmte Neurone (Veening und Barendregt 2010).

Gebildet wird der Liquor durch Ultrafiltration des Blutes in den Plexus chorioidei der vier Hirnkammern/Ventrikel. Anschließend fließt die Flüssigkeit über das Foramen Magendii und die Foramina Luschkae in die basalen Zisternen und teilt sich dann in einen kortikalen und lumbalen Zweig des Subarachnoidalraumes. Durch die dort vorhandenen Arachnoidalzotten in den Pacchioni-Granulationen wird der Liquor ohne Filtrationen in das venöse Blut drainiert (Davson und Segal 1996, Zettl et al. 2005).

Die tägliche Produktion liegt bei etwa 0,3 bis $0,4 \mathrm{ml}$ pro Minute, was etwa einer Gesamtmenge von $50 \mathrm{ml}$ pro Tag entspricht. Die Ventrikel fassen insgesamt ein Volumen von ca. 12-23 ml und der spinale Anteil des Subarachnoidalraums bis zu $30 \mathrm{ml}$. Da das durchschnittliche Liquorvolumen des Erwachsenen ca. $150 \mathrm{ml}$ beträgt, unterliegt der Liquor einem ständigen Kreislauf von Produktion und Resorption.

Liquor enthält im Normfall maximal bis zu vier Leukozyten/ $\mu$, wobei 2/3 Lymphozyten (Anteil der B-Lymphozyten ca. 1\%, im Vergleich zum Blut mit ca. 5-10\%) und 1/3 Monozyten sind. Im Gegensatz dazu sind Granulozyten und Erythrozyten, außer durch Verschleppung im Rahmen der Punktion, im unauffälligen Liquor nicht zu finden. Das Gesamteiweiß des Liquors beträgt etwa $200-400 \mathrm{mg} / \mathrm{l}$ und ist damit deutlich niedriger als das Gesamteiweiß des Blutserums mit ca. 50 g/l. Den größten Anteil des Gesamteiweißes daran 
hat das Albumin mit ca. 60\% im Blutserum und ca. 67\% im Liquor. Anhand dieses Verhältnisses, Albumin-Liquor-Serum-Quotient genannt, kann man die Blut-LiquorSchrankenfunktion beurteilen.

Der Glukosegehalt entspricht ungefähr 50-70\% der des Blutes und liegt somit zwischen 2,54,2 mmol/1 (Kilian et al. 1925).

Schon 1928 konnte bewiesen werden, dass der Liquorlaktatwert einen spezifischeren Parameter zur Beurteilung eines Infektionsverlaufes als der Glukosegehalt im Liquor darstellt (Garcia et al. 1928). Der Referenzbereich der Laktatkonzentration ist altersabhängig und liegt zwischen 1,1-1,8 mmol/1 (0-15 Jahre), 1,5-2,1 mmol/1 (16-50 Jahre) und 1,7-2,6 mmol/1 (>51 Jahre) (Kleine et al. 1979, Zettl et al. 2005). Zwischen dem Glukosegehalt und der Laktatkonzentration im Liquor besteht ein inverses Verhältnis (Killian 1925), denn sinkt der Glukosegehalt im Liquor z. B. aufgrund einer bakteriellen oder tuberkulösen Meningitis, so steigt im Zuge dessen die Laktatkonzentration an. Die Laktatanalytik ist gegenüber der Glukoseanalytik zu bevorzugen, da in diesem Fall nur eine Bestimmung im Liquor notwendig ist, pathologische Werte im Vergleich zur Glukoseanalytik deutlich früher zu finden sind und auch bei unbehandelten Patienten pathologische Werte länger nachweisbar bleiben (Schabet et al. 1986, Kleine 2005).

Grundsätzlich muss man zwischen zwei verschiedenen Laktatformen unterscheiden. Als Endprodukte des anaeroben Glukosestoffwechsels, der vornehmlich in den Astroyzten stattfindet, entstehen L- und D-Laktat. Diese werden aerob von Neuronen verstoffwechselt (Walz und Mukerji 1988). Im menschlichen Körper liegt fast ausschließlich die L-Form vor. D-Laktat ist aufgrund des geringen prozentualen Anteils am Gesamtlaktat von weniger als $1 \%$ in der Laktatanalytik diagnostisch nicht relevant. Zwar bilden einige Bakterienstämme in vitro stärker D-Laktat als L-Laktat (N. meningitidis, E.coli), was vor allem in der analytischen Differenzierung für die Erregerdiagnostik und der damit verbundenen spezifischen Therapie wegweisend sein könnte, jedoch konnte dies nicht in In-vivo-Bedingungen tierexperimentell bestätigt werden. Denn auch hier überwog deutlich die L-Laktat-Produktion (Wellmer et al. 2001). Ein signifikanter Zusammenhang beim Menschen zwischen der Schwere einer Meningitis und der D-Laktat-Produktion konnte ebenfalls nicht nachgewiesen werden (Prange 2004). Eine erhöhte Laktatkonzentration im Liquor bei z.B. schweren bakteriellen Meningitiden ist nur sehr gering dadurch bedingt, dass D-und L-Laktat durch Bakterien selbst produziert werden. Der Grund für die erhöhte Laktatkonzentration liegt in der Fähigkeit bzw. Kapazität der Neuronen, dass durch die Astrozyten gebildete Laktat zu verstoffwechseln. Durch u. a. eine bakterielle Meningitis kommt es zu einer gesteigerten 
Aktivität des Hirnparenchyms mit Beteiligung der Neuronen und Astrozyten. Durch die damit verbundene gesteigerte Laktatproduktion der Astrozyten, sinkt die Kapazität der Neurone, dieses zu verstoffwechseln und abzubauen. In der Folge kommt es zu einem Anstieg der Laktatkonzentration. Zusätzlich gehen die Neuronen in diesem Prozess mittels Glykolyse zur Energiegewinnung über, was ebenfalls den Laktakwert erhöht. Glutamat dient hierbei als Botenstoff für die Astrozyten und steigert so ihre Aktivität (Prange 2004, Wellmer et al. 2001).

Die Bestimmung der Laktatkonzentration im Liquor dient u. a. der Unterscheidung zwischen bakteriellen und abakteriellen Meningitiden. Zur Beurteilung wird jedoch keine vergleichende Serumlaktatanalyse benötigt, da sich Schwankungen der Blutkonzentration unter normalen Umständen nicht auf die Liquorlaktatkonzentration auswirken (Posner und Plum 1967). Im Fall von akut bakteriellen Meningitiden (außer Neuroborreliose) einschließlich der tuberkulösen Meningitis sind in über 90\% der Fälle Laktatwerte von $\geq 3,5 \mathrm{mmol} / 1$ aufgetreten. Handelt es sich jedoch um viral bedingte Meningitiden lassen sich nur in $<1 \%$ erhöhte Laktatwerte über 3,5 mmol/1 beobachten. Außerdem kann man beobachten, dass bei vaskulären Störungen, zerebralen Anfällen und Tumoren (primäre und sekundäre) meistens Laktatkonzentrationen von unter 3,5 mmol/1 zu finden sind (Petereit et al. 2007, Djukic et al. 2012, Kleine et al. 1979, Luft und Götz 1983).

\subsection{Einführung in die Liquordiagnostik}

Da es sich bei der Liquordiagnostik um ein sehr komplexes Thema handelt, soll im folgenden Abschnitt eine kurze Einführung in die Liquordiagnostik erfolgen.

Voraussetzung für die Liquoranalytik ist meistens eine Lumbalpunktion, die Corning 1885 als erster durchführte und durch Heinrich I. Quinckes Veröffentlichungen begründet und somit als Routinediagnostik aufgenommen wurde.

Die Punktion wird mithilfe einer Punktionsnadel durchgeführt. Man unterscheidet zwei verschiedene Arten von Punktionsnadeln, zum einen gibt es die aufgrund ihrer konischrunden Spitze „,atraumatische“ Sprotte-Nadel, die besonders häufig in der Routinediagnostik benutzt wird (Storch-Hagenlocher 2006a), zum anderen gibt es außerdem die QuinckeNadel, die eine scharf geschliffene Spitze besitzt und daher auch als „traumatische“ Nadel bezeichnet wird. 
Um den korrekten Punktionsort zu finden (Ziel sind die Zwischenräume LWK3/4, LWK 4/5 oder LWK 5/S1), orientiert man sich zunächst an anatomischen Fixpunkten am menschlichen Körper. Zunächst sollte man die beiden Cristae iliacae suchen, da auf deren gedachter Verbindungslinie der Processus spinosus des 4. LWK liegt. Mithilfe dieser Stelle kann man die möglichen Punktionsorte, die ungefähr einen Zentimeter darunter liegen, finden. Nach der Wahl der Nadel und dem Finden der Punktionsstelle müssen eine gründliche Desinfektion sowie ein steriles Abdecken dieses Areals stattfinden (Gröschel et al. 2008).

Die anschließende Punktion wird nach Verabreichung eines Lokalanästhetikums und in liegender oder sitzender Position des Patienten durchgeführt, hierbei ist aber zu beachten, dass die Punktion im Sitzen als einfacher anzusehen ist. Wesentlich ist eine entspannte Lage für den Patienten mit möglichst maximaler Ventralflexion und Dehnung der LWS („Katzenbuckel“) sowie flektierten Beinen. (Storch-Hagenlocher 2006a). Sollte der Patient nach Gabe des Lokalanästhetikums weiterhin ängstlich und verspannt sein, so kann zusätzlich ein Benzodiazepin in niedriger Dosierung verabreicht werden (Gröschel et al. 2008).

Als Indikation für eine Liquorpunktion gilt unter anderem die Diagnostik entzündlicher Erkrankungen (Meningitis, Multiple Sklerose, Neuroborreliose, Polyradikulitis), der Nachweis von Tumorzellen, die Diagnostik neurodegenerativer Erkrankungen. Außerdem kann eine Liquorpunktion durchgeführt werden für die Liquordruckmessung (z. B. bei Pseudotumor cerebri), den Nachweis einer Subarachnoidalblutung sowie zur Therapie einer idiopathischen intrakraniellen Hypertension oder eines Normaldruckhydrocephaluses und der Injektion von Medikamenten in den Liquorraum (Oschmann et al. 2005).

Kontraindikationen sind u. a. kardiorespiratorische Erkrankungen, die die notwendige Lagerung nicht erlauben, ein klinisch manifester erhöhter intrakranieller Druck, da dadurch die Gefahr der zerebralen Einklemmung besteht, sowie lokale Entzündungen am Punktionsort, da dadurch die Gefahr der Keimverschleppung besteht. Des Weiteren sollte vor jeder Punktion der Gerinnungsstatus des Patienten geprüft werden, um mögliche Gerinnungsstörungen ausschließen zu können, hierbei definiert man eine Thrombozytenzahl $<50000 /$ Einheit als eine relative Kontraindikation sowie eine Thrombozytenzahl < 20000/Einheit als absolute Kontraindikation. (Diener und Weimer 2012)

Die Liquorbeurteilung erfolgt sowohl makroskopisch als auch mikroskopisch. Ein wichtiger Punkt für die mikroskopische Beurteilung des Liquors ist, dass diese zunächst immer im 
Zusammenhang mit dem Punktionsort und dem Patientenalter stattfinden muss, da die chemische Zusammensetzung kompartimentellen (äußere/innere Liquorräume, lumbale und kraniale Liquorverteilung) Variationen unterliegt (Conly und Ronald 1983) und altersabhängig ist.

Die primäre makroskopische Beurteilung des Liquors ist leicht und schnell, wodurch man erste vage Rückschlüsse auf die Ursache für die Verfärbung des Liquors schließen kann. Visuell kann man zunächst unterscheiden, ob ein blutiger oder ein trüb-flockiger Liquor vorliegt.

Ein blutiger Liquor kann auf eine akute Blutung in die Liquorräume hinweisen, wie sie z.B. bei einer Subarachnoidalblutung auftritt, jedoch muss auch eine Blutbeimischung durch die Punktion selbst in Betracht gezogen werden, da diese den Liquor auch blutig färben kann und es somit zu einer Fehlinterpretation kommen könnte.

Für die schnelle Differenzierung zwischen artifiziell-blutigem Liquor und blutigem Liquor durch Einblutungen in die Liquorräume hat sich die Durchführung der 3-Gläser-Probe bewährt (Masuhr und Neumann 2007). Die 3-Gläser-Probe beinhaltet das Befüllen von drei sterilen Liquorröhrchen mit jeweils 1-2 ml Liquor direkt aus der Punktionsstelle nacheinander. Diese Liquorröhrchen selbst sind aus Polystyrol und dazu durchsichtig, unbeschichtet und konisch zulaufend. Bei Abnahme der Intensität der Blutbeimengung im Verlauf der drei Röhrchen ist von einer artifiziellen Blutbeimengung auszugehen. Sollte es jedoch zu keiner Abnahme der Intensität kommen, so ist von einer Blutung in die Liquorräume auszugehen.

Zur weiteren Unterscheidung sollte beim Vorliegen eines blutigen Liquors eine schnellstmögliche Zentrifugation bei 200-300 g durchgeführt werden, denn entsteht dadurch ein klarer Überstand, so kann dies ein weiterer Hinweis auf eine artifizielle Blutbeimengung sein. Jedoch kann auch nach einer kurz zurückliegenden Blutung der Überstand nach Zentrifugation klar sein.

Kommt es nach dem Zentrifugieren zur Bildung eines xanthochromen Überstandes, ist dies hinweisend auf eine ältere Blutung. Aber auch bei einer starken Erhöhung der Eiweißkonzentration im Liquor (z. B. Polyradikulitis) und bei einer schweren Hyperbilirubinämie (Ikterus) findet sich ein xanthochromer Liquor (Storch-Hagenlocher 2006b, Masuhr und Neumann 2007).

Ein trüb-flockiger Liquor entsteht durch eine starke Pleozytose (Zellzahlerhöhung im Liquor $>1000 \mu \mathrm{l}$ ) sowie Proteinerhöhung und spricht in der Regel für eine eitrige Meningitis. Eine isolierte Eiweißerhöhung kann ebenfalls zur trüben Verfärbung des Liquors führen. So 
genannte „Spinnwebgerinnsel“ sind makroskopisch sichtbare grobe Fibringerinnsel, die häufig mit einer tuberkulösen oder Kryptokokken- (Cryptococcus neoformans) Meningitis assoziiert sind (Staib et al. 1990).

Abschließend lässt sich formulieren, dass die makroskopische, visuelle Beurteilung des Liquors eine schnelle und einfache Methode ist, um erste wegweisende Anhaltspunkte zu erlangen und eine zielgerichtete Anschlussdiagnostik einzuleiten.

Die mikroskopische manuelle Zellzählung erfolgt meistens mit Hilfe der Fuchs-RosenthalKammer $\left(3,2 \mu \mathrm{l}\right.$ Volumen, $16 \mathrm{~mm}^{2}$ Fläche, 0,2 $\mathrm{mm}$ Tiefe) nach Anfärben mit Gentianaviolett. Für dieses Vorgehen wird nativer und möglichst frischer Liquor benötigt. Eine Alternative zur manuellen Zellzählung ist die automatisierte Zellzählung mit verschiedenen zytometrischen Systemen. Jedoch haben zahlreiche Untersuchungen über die Analogie und Genauigkeit (Hoffmann und Janssen 2002) der unterschiedlichen Systeme im Vergleich zur manuellen Zählung gezeigt, dass diese in keiner Weise von den vorliegenden Methoden der automatisierten Zelldifferenzierung ersetzt werden kann (Storch-Hagenlocher 2006b).

Neben der konventionellen Zytologie zählt die Immunozytologie ebenfalls zur Analytik. Dabei ist jedoch zu beachten, dass der fast zellfreie Liquor fast immer einer vorangehenden Zellanreicherung bedarf und sich der Ausstrich nicht einfach anfertigen und untersuchen lässt, wie man es bei einem Blutausstrich machen kann. Dabei sollte ein großes Augenmerk darauf liegen, dass die Morphologie der Zellen erhalten bleibt und der Verlust dieser klein gehalten wird. Als Alternativen stehen dafür die Methode des Sedimentierkammerverfahrens oder die Methode der Zytozentrifugation zur Verfügung. Als weitere Methode zur Steigerung der Zellausbeute kann man die Vorzentrifugation bei ca. 2200 Umdrehungen/Minute (Storch-Hagenlocher 2006b) benutzen.

Anschließend folgt die Färbung (May-Grünwald-Giemsa-Färbung als Standard) und/oder Immunzytochemie des Präparates.

Des Weiteren zählen die Immunchemie/Immunkomplex-Analytik, sowie die elektrophoretischen Nachweisverfahren $\mathrm{zu}$ den methodischen Grundlagen der Liquoranalytik. Dabei dient die Immunchemie/Immunkomplex-Analytik zum spezifischen Nachweis von Makromolekülen (z.B. Proteine) in Geweben und Körperflüssigkeiten. Für diesen Nachweis kommen u.a. die Nephelometrie und Turbidimetrie, der Immunoassay, die Agglutination und die radiale Immundiffusion und Elektroimmundiffusion zum Einsatz (Reiber 2006b) in Frage. Durch das Hinzufügen von Antiseren (Antikörpern) können 
dadurch spezifische Antigene nachgewiesen werden, hierzu nutzt man die Eigenschaft der Antigen-Antikörper-Bindung, die zu extrem stabilen Immunkomplexen führt.

Für den Nachweis von Proteinen in Serum und Liquor nutzt man auch die elektrophoretischen Nachweisverfahren. Bestandteil der Proteinelektrophorese ist, dass die Proteine, die sich auf einem Trägermaterial befinden, einem elektrischen Feld ausgesetzt werden. In diesem elektrischen Feld wandern diese Proteine in Abhängigkeit von Molekülgröße, isoelektrischem Punkt, Temperatur und pH-Wert des Puffers unterschiedlich weit und lassen sich so auswerten. Dabei ist jedoch auch zu beachten, dass das Verfahren der Proteinelektrophorese für die Analytik des Liquors heutzutage, im Gegensatz zur Serumelektrophorese des Blutes, obsolet ist. Als Verfahren wurde hier die RocketElektrophorese (Elektroimmundiffusion) etabliert (Reiber 2006b).

Die intrathekale IgG-Synthese, die u. a. im Rahmen von z. B. chronisch-entzündlichen Krankheiten viralen und bakteriellen ZNS-Infektionen auftritt, lässt sich sehr zuverlässig durch die isoelektrische Fokussierung nachweisen. Hierbei handelt es sich um eine zusätzliche Methode der qualitativen Nachweisverfahren, die eine sehr hohe Trennschärfe/Sensitivität besitzt (Wurster 2005). Bei dieser Methode macht man sich den isoelektrischen Punkt zur Nutze. Dabei handelt es sich um einen bestimmten pH-Wert, an dessen Punkt die Nettoladung des Proteins gleich null ist. Im Fall der isoelektrischen Fokussierung wandern die Proteine, die sich auf einer Trägersubstanz (Agarosegel) befinden, in einem elektrischen Feld mit pH-Gradienten abhängig von ihrer Ladung zur Anode bzw. Kathode. Sobald sie ihren isoelektrischen Punkt erreicht haben, lassen sie sich durch die „Fokussierung“ an dieser Stelle auswerten. Der Nachweis von oligoklonalen IgG-Banden im Liquor/Serum erfolgt nach der isoelektrischen Fokussierung mit Hilfe des Immunoblot oder der Silberfärbung (Reiber 2006b).

Zur weiteren Diagnostik zählt auch die neuropathologische Liquordiagnostik, die essentiell für die zytologische Untersuchung ist. Mithilfe der oben genannten Verfahrensweisen kann man eine Differenzierung der im Liquor vorkommenden Zellen durchführen. Besonders wichtig für die neuropathologische Untersuchung ist vor allem der unmittelbare Transport in das weiterverarbeitende Labor, da es im Liquor zu einer sehr schnellen Autolyse der Zellen kommt.

In einem normalen Liquor finden sich vorrangig zwei verschiedene Zelltypen, die unterschieden werden in die Lymphozyten und Monozyten, wobei die Lymphozyten häufiger zu finden sind. Neben den Lympho- und Monozyten finden sich gelegentlich noch Granulozyten sowie Erythrozyten, die jedoch primär durch die Punktion selbst in den Liquor gelangen (Kölmel 2005). 
Bei den im Liquor vorkommenden Lymphozyten handelt es sich meist um T-Lymphozyten, die klein und isomorph sind und zusätzlich durch einen leicht ovalen Kern mit einem schmalen Zytoplasma auffallen. Die Monozyten imponieren durch einen hufeisenförmigen Kern, sowie durch ein Zytoplasma, das von Vakuolen durchsetzt ist (Kölmel 2005).

Zusätzlich kann der normale Liquor noch epitheliale Zellen, die aus dem Plexus choroideus oder dem Ependym stammen, sowie Phagozyten, die der Abwehr von Fremdpartikeln dienen und durch phagozytiertes Material im Zytoplasma imponieren.

Bei entzündlichen Prozessen kommt es zu einer Migration von Granuloyzten in den Liquor, als Folge dessen kommt es durch den anaeroben Stoffwechsel der Granulozyten zu einem Laktatanstieg im Liquor. Neutrophile Granulozyten besitzen mehrfach segmentierte Kerne und kommen vor allem nach akuten Reizen, wie z.B. einem Schlaganfall oder aber auch bei bakteriellen Geschehnissen und viralen Meningitiden vor. Eosinophile Granulozyten zeigen einen brillenförmigen Kern und treten besonders häufig in der Heilungsphase nach entzündlichen Phasen auf. Außerdem zeigt sich auch eine eosinophile Reaktion im Rahmen von malignen Tumoren, ob jedoch eine prognostische Relevanz dieser Reaktion besteht und ob eine pathogenetische Rolle vorliegt ist unklar, sodass dies stark diskutiert wird (von Wasielewski et al. 2000).

Transformierte Lymphozyten und Plasmazellen treten im Rahmen jeglicher akuter oder subakuter Entzündungsreaktionen im ZNS auf. Reife Plasmazellen imponieren dabei häufig durch einen runden Kern mit grobem Chromatingerüst und einem typischen Radspeichenmuster. Bei viralen und bakteriellen Meningitiden zeigt sich häufig ein mononukleäres Zellbild mit einer ausgeprägten granuolzytären Transformation, wobei sich dieses Bild bei den viralen Meningitiden eher zeigt als bei den bakteriellen.

Maligne Zellen sind größer als Lymphozyten und zeigen eine hohe Mitose- und Zellteilungsrate. Diese Zellen können einzeln oder in einem Zellverband vorliegen und sind mehrkernig, wobei die Kern-Plasma-Relation häufig zugunsten des Kerns verschoben ist. Die Kerne sind meist polymorph, bizarr geformt und besitzen eine aufgelockerte Chromatinstruktur. Eine Zuordnung der Tumorzellen zu bestimmten Organen ist meist nicht möglich.

Zusätzlich zu der Zytologie sollte auch noch eine Immunozytochemie stattfinden, da diese die Sensitivität der bereits durchgeführten Zytologie erhöht. Im Rahmen der Zytochemie werden Tumorzellen mit Hilfe der Expression von Zytokeratinen nachgewiesen (Hau et al. 2015). 
Im Rahmen der Immunozytochemie ist ebenfalls die Bestimmung und Charakterisierung von Tumormarkern möglich. Ein Tumormarker weist mit hoher Spezifität auf ein vorliegendes Karzinom hin, jedoch ist die Zuordnung zu einem betroffenen Organ nur schwer möglich. Nachweisbare Tumormarker im Liquor sind u.a. das carcinoembryonale Antigen (CEA), das beta- humane Choriongonadotropin (beta-HCG) und das alphaFetoprotein (AFP). Der CEA-Wert kann zum Beispiel als diagnostisches Kriterium für die Meningeosis neoplastica hinzugezogen werden. Das carcinoembryonale Antigen kann unter anderem im Rahmen eines Kolonkarzinoms, eines Lungenkarzinoms, Lebermetastasen, aber zum Beispiel auch bei einer Pneumonie, im Serum erhöht sein.

\subsection{Zielsetzung}

Bei dem Verdacht auf eine Meningeosis neoplastica zählt die Liquorpunktion und die damit verbundene Untersuchung des Liquors zum wichtigsten Diagnostikum.

Wie bereits in 1.1 erwähnt, kann es im Rahmen einer Meningeosis neoplastica zu einer Erhöhung des Liquorlaktates kommen (Wasserstrom et al. 1982).

Jedoch kann es auch im Rahmen anderer entzündlicher Prozesse im ZNS zu einer Erhöhung des Laktatwertes im Liquor kommen, des Weiteren ist eine Abhängigkeit der Laktatkonzentration vom Alter des Patienten bekannt.

Diesen Vorarbeiten Rechnung tragend, stellen sich u. a. Fragen, z.B. ob es möglich ist, nur anhand des Nachweises von Laktat im Liquor auf die Diagnose Meningeosis neoplastica zu schließen und ob es im Vergleich zu anderen entzündlichen ZNS-Prozessen zu deutlich höheren oder niedrigeren Werten kommt.

Aufgrund dieser Fragen und einer dürftigen Datenlage speziell bezogen auf das Liquorlaktat bei einer der Meningeosis neoplastica sind Ziele dieser retrospektiven Studie:

1. Analyse der Liquor-Routineparameter des Patientenkollektives

2. Überprüfung, ob es eine Korrelation zwischen dem Liquorlaktat und der Zellzahl, sowie des Gesamtproteins im Liquor und der Zellzahl gibt

3. Darstellung der Liquorlaktatwerte und Vergleich der Ergebnisse mit primären entzündlichen ZNS- Prozessen, insbesondere der tuberkulösen Meningitis

4. Darstellung der Symptome, die in vorliegenden Arztbriefen der Patienten bei Erstdiagnose beschrieben wurden 


\section{$2 \quad$ Material und Methoden}

\subsection{Patientenkollektiv}

Bei dem Patientenkollektiv, von dem Daten ausgewertet wurden, handelt es sich um weibliche und männliche Patienten unterschiedlichsten Alters (zwischen 16 und 97 Jahren). Diese 132 Patienten stellten sich zwischen 2001 und 2012 in der Universitätsklinik Göttingen, im Evangelischen Krankenhaus Weende sowie umliegenden Krankenhäusern aufgrund verschiedener Symptomatik vor und litten u.a. an Kopfschmerzen, Meningismus oder Krampfanfällen. Knapp 70\% dieser Patienten hatten zum Zeitpunkt der erstmaligen Aufnahme einen Karnowsky-Index zwischen 60-80\%. Bei allen Patienten wurden im Rahmen der Analyse des Liquorsedimentes Tumorzellen nachgewiesen (Einschlusskriterium dieser Studie).

Es erfolgte keine Rekrutierung von Patienten oder Probanden, es handelte sich um eine retrospektive Auswertung der Daten, die aus diagnostischen Gründen erhoben wurden, so dass nur die Patienten, die aus diagnostischen oder therapeutischen Gründen für eine Lumbalpunktion eingewilligt hatten und diese anschließend erhielten, in die Untersuchung eingeschlossen werden. Ausgeschlossen werden alle anderen Patienten, die nicht lumbalpunktiert wurden.

Alle personenbezogenen Daten wurden anonymisiert, so dass hieraus keine Hinweise auf den Namen, Adresse oder Geburtsdatum des Patienten gewonnen werden können.

Entsprechend dieser Vorgehensweise ist das Einholen einer Einverständniserklärung der Patienten nicht vorgesehen.

Ein Votum der Ethikkommission mit der Erlaubnis zur Durchführung dieser Studie liegt vor.

Neben den in 2.2. genannten Labortests wurden auch die CT und MRT-Befunde, insofern diese vorlagen, in Auswertung mit hinzugenommen.

\subsection{Labortests}

\subsubsection{Fuchs-Rosenthal-Zählkammer und Zelldifferenzierung}

Die Zellzahl im Liquor, der dafür mit einer Karbolfuchsin-Lösung angefärbt wird, wird mit Hilfe der Fuchs-Rosenthal-Zählkammer ermittelt. Sollten mehr als 4 Zellen pro $\mu$ l vorliegen, 
handelt es sich definitionsgemäß um eine Pleozytose. Tumorzellen können aufgrund ihrer zytologischen Atypien nachgewiesen werden. Sie fallen vor allem durch eine Zunahme der Kern/Plasma-Relation sowie durch eine unregelmäßige Zellkernform. Des Weiteren zeigen sie häufig prominente Nucleoli, ein basophiles Zytoplasma und eine allgemeine Zunahme der Zellgröße im Vergleich zu normalen Entzündungszellen. Abhängig vom Primarius können Tumorzellen gelegentlich eine Schleimproduktion oder Pigmentierung zeigen (Liu et al. 2009). Anschließend erfolgte die Anreichung der Zellen des nativen Liquors in einer Zentrifuge (Omnifuge 2.0 ORS der Firma Thermo Scientific) mit 700 Umdrehungen/min für $10 \mathrm{~min}$ bei $21^{\circ} \mathrm{C}$ und sowie Färbung (May-Grünwald-Giemsa-Färbung) für die Differenzierung der einzelnen Zellen per Mikroskop in Erythrozyten, Monozyten, Lymphozyten und Granulozyten.

\subsubsection{May-Grünwald-Giemsa-Färbung}

Im Anschluss an die oben beschriebene Zellanreicherung durch Zytozentrifugentechnik erfolgte die Fixierung und Färbung der Zellpräparate mithilfe der May-Grünwald-GiemsaFärbung (Firma Merck, Darmstadt, Deutschland). Die Anfärbung läuft in mehreren Schritten ab. Zunächst wird die May-Grünwald-Eosin-Methylen-Blau-Lösung auf die Zellpräparate aufgetragen, die 2 Minuten auf das Präparat einwirken muss. Nach dem Einwirken dieser Lösung wird $1 \mathrm{ml}$ Pufferlösung aufgetragen, die nochmals 1 Minute einwirken muss und danach abgegossen wird. Anschließend erfolgt das Auftragen und das Einwirken von verdünnter Giemsa-Azur-Eosin-Methylen-Blau-Lösung (auf $10 \mathrm{ml}$ Pufferlösung 15 Tropfen Giemsa-Lösung) über 8 Minuten und ein darauffolgendes Abspülen mit $\mathrm{H}_{2} \mathrm{O}$. Nach einer Trocknungszeit von 15 Minuten werden die Präparate mit einem Eindeckmittel (Depex, Fa. Serva, Heidelberg, Deutschland) abgedeckt.

\subsubsection{Laktat}

Für die Laktatbestimmung wurde eine enzymatische Methode mittels Laktat-Oxydase genutzt. Die Laktat-Oxydase spaltet Laktat in Pyruvat und Wasserstoffperoxyd. Durch anschließende Zwischenreaktionen entsteht zum Schluss ein rot gefärbtes Chinonimin, dessen Farbintensität proportional zur Laktatkonzentration ist. Die Farbintensität wurde mit dem ELISA-Reader von SLT/Easy-Fit, Programm mit Referenzfilter 620 nm, gemessen. Ab einem Wert von > 2,4 mmol/l würde man von einer Erhöhung des Laktatwertes sprechen (Petereit et al. 2007). 


\subsubsection{Gesamtprotein}

Die Bestimmung des Gesamtproteins erfolgte anhand der kinetischen Auswertung der maximalen Streulichtintensität in 40 \%iger Trichloressigsäure-Lösung (Gerät Dosascat der Firma Dosatec ${ }^{\circledR}$ GmbH, Gilching, Deutschland) (Reiber 1980).

\subsubsection{Albumin}

Für den Nachweis des Albumins wird das Verfahren der immunchemischen Nephelometrie mit Zweipunkt- oder kinetischer Analytik genutzt (Gerät BN ${ }^{\circ}$ ProSpec des Herstellers Siemens Healthcare Diagnostics Inc., Terrytown, New York, USA).

\subsubsection{IgG, IgA und IgM im Liquor und im Serum}

Die Bestimmung der Liquor- und Serumkonzentrationen von IgG, IgA, und IgM erfolgt mit Hilfe eines immunchemischen Detektionsverfahrens (Gerät BN ProSpec des Herstellers Siemens Healthcare Diagnostics Inc., Terrytown, New York, USA). Durch diese nephelometrische Bestimmung kann das Liquor/Serum Verhältnis für IgG, IgA, IgM und Albumin berechnet werden. Das IgG-, IgA-, und IgM- Liquor/Serum-Verhältnis wurde gegen das Liquor/Serum-Albumin-Verhältnis ( $\left.Q_{\text {Albumin }}\right)$ entsprechend dem Nomogramm von Reiber und Felgenhauer aufgezeichnet (Reiber und Felgenhauer 1987). Der altersabhängige Referenzbereich für QAlbumin wurde berechnet als $\mathrm{Q}_{\text {Albumin }}=\left(4+\right.$ Alter/15) $\times 10^{-3}$ (Reiber et al. 2001).

\subsubsection{Intrathekales oligoklonales IgG}

Für den Nachweis einer intrathekalen oligoklonalen IgG-Synthese nutzt man das Prinzip der isoelektrischen Fokussierung. Für den Vergleich der Banden im Liquor und Serum wurden Liquor und Serum so verdünnt, dass gleiche IgG-Mengen aufgetragen werden (Reiber und Felgenhauer 1987).

\subsubsection{CEA-Bestimmung}

Der CEA-Wert eignet sich weniger als diagnostisches Kriterium für die Erstdiagnose eines Tumorleidens, sondern wird als Verlaufskontroll-Kriterium verwendet (Vogt-Schaden 2006). Jedoch kann der CEA-Wert als diagnostisches Kriterium für die Meningeosis neoplastica hinzugezogen werden. 
Für die Analytik wird aufgrund der sehr niedrigen CEA-Konzentration im Liquor ein Liquorvolumen von 2-3 $\mathrm{ml}$ benötigt.

Im Rahmen der Analytik erfolgt ein Enzymimmunoassay mit antikörperbeschichteten Kugeln, die anschließend in der Liquorprobe inkubiert werden (Petereit 2007).

\section{$\underline{\text { 2.2.8 Ferritin }}$}

Die Ferritin-Synthese erfolgt auch im Normalzustand im ZNS, sodass knapp 98\% des Liquor-Ferritins aus dem ZNS stammt. Der Referenzbereich liegt bei $10 \mathrm{ng} / \mathrm{ml}$. Höhere Werte findet man bei Begleitblutungen bei HSV-Encephalitis und Tumoren, sowie bei einer bakteriellen Meningitis.

Für die Diagnostik benötigt man ca. 0,5 ml Liquor, der dann mit Hilfe eines ELISA oder Nephelometrie analysiert wird (Petereit 2007).

\subsubsection{Computertomographie}

Die Computertomographie ist ein Röntgenverfahren, bei dem transversale Schichten des menschlichen Körpers erzeugt werden. Durch dieses Verfahren können somit Organe und Gewebe 2-dimensional und überlagerungsfrei dargestellt werden. Während der Untersuchung rotiert die Röntgenröhre bei gleichzeitiger Tischbewegung um den Patienten. Die dabei ausgesendeten Röntgenstrahlen sind so breit wie die gewünschte Schichtdicke und erfassen den gesamten Körperquerschnitt. Der Detektor, der sich gegenüber der Röntgenröhre befindet, misst u.a. die Unterschiede der Intensität der Röntgenstrahlen und wandelt diese in elektrische Signale um. Diese Signale werden wiederum in einem Bildrechner verarbeitet. Die gemessenen Schwächungswerte werden dann mithilfe gefalteter Rückprojektionen in das Schichtbild umgewandelt (Mayor 2015).

\subsubsection{Magnetresonanztomographie}

Im Gegensatz zu der Computertomographie, bei der mit Röntgenstrahlung gearbeitet wird, werden bei der Magnetresonanztomographie mithilfe eines starken Magnetfeldes die Schnittbilder erstellt. Ein großer Vorteil besteht darin, dass insbesondere das Weichteilgewebe wie das Gehirn und die inneren Organe mittels der Magnetresonanztomographie sehr gut dargestellt werden. Ein weiterer wichtiger Vorteil ist, dass auch dynamische Prozesse, wie z.B. Stoffwechselvorgänge im Gehirn, abgebildet werden können (Siemens Healthcare 2017). 


\subsection{Statistik}

Die statistische Datenanalyse erfolgte mittels GraphPad Prism Software (GraphPad Software, La Jolla, USA). Die Ergebnisse sind beim Vorliegen einer Gauß'schen Normalverteilung mittels Mittelwert \pm Standardabweichung (SD) oder bei nicht normal verteilten Daten mittels Median und 25\% und 75\% Perzentile (Q25; Q75) dargestellt. Der Vergleich unterschiedlicher Häufigkeiten erfolgte mittels Fisher's Exact Test. Für die univariante Analyse wurde, insofern keine Normalverteilung vorlag, der U-Test genutzt. Die Korrelation zwischen Zellzahl im Liquor und Laktat im Liquor wurde mithilfe des Spearman's Rangkorrelationskoeffizienten rS errechnet. P-Werte $\leq 0,05$ galten als statistisch signifikant. Die statistische Spannweite wurde mit min. und max. dargestellt. 


\section{Ergebnisse}

Zwischen 2001 und 2014 stellten sich 132 Patienten aufgrund verschiedener Symptomatik in der Universitätsklinik Göttingen (107 Patienten), im Evangelischen Krankenhaus Weende (2 Patienten) sowie umliegenden Krankenhäusern (23 Patienten) vor.

Das Durchschnittsalter bei den Patienten lag bei 59,1 \pm 29,1 Jahren und das Geschlechtsverhältnis lag bei 77 Frauen (58,3\%) zu 55 Männern (41,6\%).

Die Liquorprotokolle wurden nach folgenden Parametern untersucht und ausgewertet:

1. Punktionsdatum

2. Laktat

3. Zellzahl

4. Erythrozyten

5. korrigierte Zellzahl

6. maligne Zellen

7. zytopathologischer Befund (Abt. Pathologie)

8. Lymphozyten

9. Monozyten

10. Granulozyten

11. Plasmazellen

12. Gesamtprotein

13. Albuminquotient

14. intrathekale IgG-Synthese

15. intrathekale IgA-Synthese

16. intrathekale IgM-Synthese

17. CEA

18. Ferritin

Die Arztbriefe wurden nach folgenden Symptomen durch geschaut und ausgewertet:

1. Kopfschmerz

2. Meningismus

3. Hirnnervenparesen

4. Fieber

5. psychische Symptome (am häufigsten Verwirrtheit und Vigilanzminderung) 
6. radikuläre Symptome obere Extremität

7. radikuläre Symptome untere Extremität

8. Querschnittssymptomatik

9. Sensibilitätsstörung allgemein

10. Hemiparese

11. Krampfanfälle

12. Aphasie

13. Gedächtnisstörungen

14. intrakranielle Druckerhöhung

\subsection{Vorerkrankungen und Symptome bei Aufnahme}

Das Mammakarzinom war mit 32,6\% die häufigste Grunderkrankung in dem vorliegenden Patientenkollektiv. Nach dem Mammakarzinom war das Bronchialkarzinom (25,0\%) am zweithäufigsten vertreten, dicht gefolgt von den hämatologischen Erkrankungen (Leukämien, Lymphome) mit 21,2\%.

In diesem Patientenkollektiv waren die gastrointestinalen Tumoren mit 8,3\% häufiger als Grunderkrankung vertreten als Hauttumoren 3,8\%.

Weitere 9,1\% machen „sonstige Tumoren“ aus, zu denen zählen u.a. urologische Tumoren, Augentumoren sowie solide Hirntumoren und spinale Raumforderungen. 


\section{Diagramm 1: Übersicht der Grunderkrankungen}

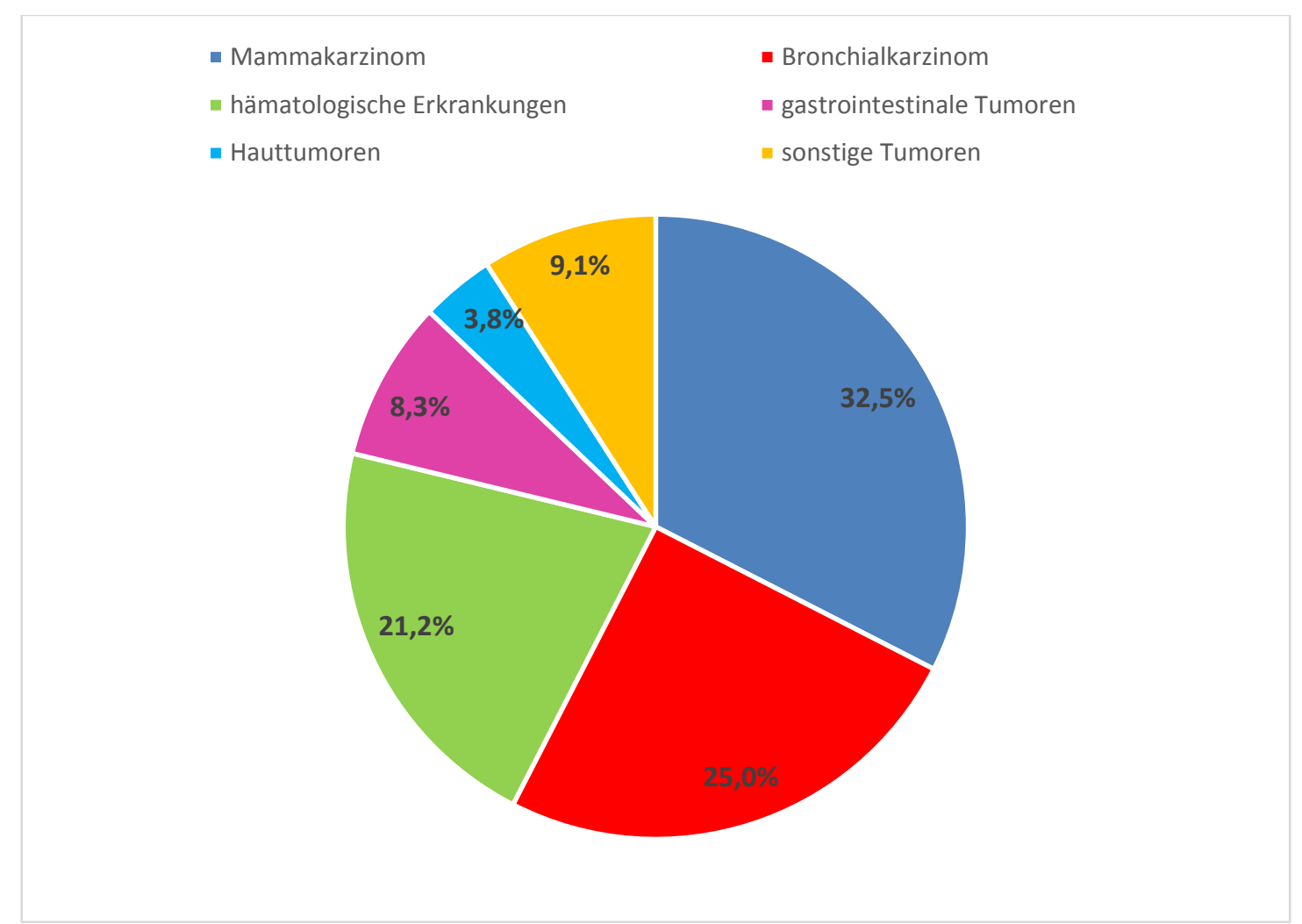

Diagramm 1: Das Mamma- und das Bronchialkarzinom waren in diesem Patientenkollektiv die häufigsten Grunderkrankungen. Die Hauttumoren sind überraschenderweise jedoch sehr selten als Grunderkrankung. Zu der Kategorie der „sonstigen Tumoren“ zählen u.a. urologische Tumoren, Augentumoren sowie solide Hirntumoren und spinale Raumforderungen. Diese traten in diesem Patientenkollektiv jedoch sehr selten auf.

Eine Übersicht der klinischen Symptomatik bei Aufnahme ist in der Tabelle 1 aufgelistet. Die klinischen Symptome beziehen sich auf den Zeitpunkt bei Aufnahme vor der ersten Liquorpunktion. 
Tabelle 1: Übersicht der Symptome bei Aufnahme

\begin{tabular}{|l|c|}
\hline Parameter & $\begin{array}{l}\text { Alle Patienten } \\
(\mathbf{n = 1 3 2})\end{array}$ \\
\hline radikuläre Symptome & 64 \\
\hline Hirnnervenparese & 55 \\
\hline psychische Symptome & 43 \\
\hline Cephalgien & 25 \\
\hline Hemiparese & 23 \\
\hline erhöhter intrakranieller Druck & 22 \\
\hline Sensibilitätsstörungen (andere als radikuläre) & 18 \\
\hline Querschnittssymptomatik & 17 \\
\hline Sprachstörungen & 15 \\
\hline Meningismus & 12 \\
\hline Gedächtnisstörungen & 11 \\
\hline Krampfanfälle & 10 \\
\hline Fieber & 2 \\
\hline
\end{tabular}

Insgesamt 64 von 132 Patienten klagten in der Aufnahmeuntersuchung über eine radikuläre Symptomatik. Somit sind die allgemeinen radikulären Symptome mit 48\% das am häufigsten beschriebene Symptom bei Aufnahme der Patienten. Jedoch sind die allgemeinen radikulären Symptome noch einmal aufzuteilen in radiukläre Symptome obere Extremität motorisch und sensibel sowie in radikuläre Symptome untere Extremitäten motorisch und sensibel und den Anteil derer, die zusätzlich eine Querschnittssymptomatik zeigten. 


\section{Diagramm 2: Aufteilung radikuläre Symptome}

- rad. Sympt. untere Extrem. motor. - rad. Sympt. untere Extrem. sens.

- rad. Sympt. obere Extrem. motor. - rad. Sympt. obere Extrem. sens.

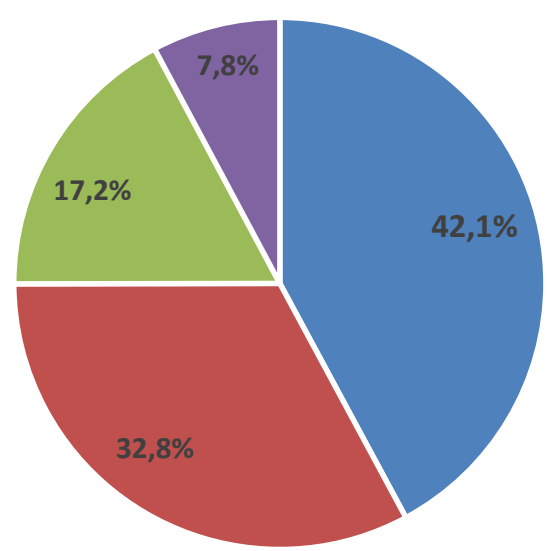

Diagramm 2: Insgesamt 27 von 64 Patienten (42,1\%), bei denen eine radikuläre Symptomatik beschrieben wurde, klagten in der Aufnahmeuntersuchung über eine radikuläre motorische Symptomatik in den Beinen, wobei bei 17 Patienten, die solche eine Symptomatik zeigten eine Querschnittssymptomatik festgestellt werden konnte. 21 von 64 Patienten (32,8\%) Patienten klagten über eine radikuläre sensorische Symptomatik in den Beinen. Von den oben genannten 64 Patienten klagten insgesamt 16 Patienten über eine radikuläre Symptomatik im Bereich der oberen Extremitäten, wobei 11 Patienten diese Symptomatik in den motorischen Anteilen beschrieben und nur 5 Patienten sensible radikuläre Ausfälle zeigten.

Die Hirnnervenparese mit $42 \%$ ist das zweithäufigste diagnostizierte Symptom bei Aufnahme.

Knapp 32,6\% der 132 Patienten klagten über psychische Symptome, am häufigsten über Verwirrtheit und Vigilanzminderung.

Bei 18,9\% der vorgestellten Personen lagen starke Cephalgien vor. 22 Patienten gaben Übelkeit und Erbrechen als einer ihrer Hauptsymptome an, 11 von ihnen klagten über zusätzliche Cephalgien.

Bei 10 Patienten konnte die Erstdiagnose der Meningeosis neoplastica, durch durchgeführte Liquorpunktion in der differentialdiagnostischen Abklärung, im Rahmen neu aufgetretener Krampfanfälle gestellt werden. 


\subsection{Liquorveränderungen bei der Meningeosis neoplastica}

\subsubsection{Zellzahlveränderungen}

Die Zellzahl im Liquor war bei 66 Patienten erhöht $(>4$ Zellen/ $\mu$ l) und bei 66 Patienten normal ( $\leq 4$ Zellen/ $\mu$ l). Im Allgemeinen kann man sagen, dass die Spannweite der Zellen von 0 bis hin zu 4692 Zellen/ $\mu$ l reichte. Bei insgesamt 18 Patienten (13,6\%) kam es zu einer Erhöhung der Zellzahl von mehr als 100 Zellen/ $\mu$ l. Maligne Zellen wurden in allen Liquorproben gefunden. Die Differenzierung der Zellen im Liquor in Lymphozyten, Monozyten und Granulozyten wurde bei 55 Patienten durchgeführt, wobei 28 von den oben genannten 55 Patienten eine normale Zellzahl hatten und 27 Patienten eine Erhöhung der Zellzahl im Liquor aufwiesen.

Die Lymphozyten waren die am häufigsten auftretende Zellart. In 52,7\% kam es zu einem Nachweis von Lymphozyten in den Liquorproben, wobei es bei keinem Patienten zu einem Lymphozytenanteil von weniger als 50\% gekommen ist. Im Liquor der Patienten mit $>4$ Zellen/ $\mu$ l zeigte sich ein signifikant vermehrtes Auftreten von Lympho- und Granulozyten im Vergleich zu Patienten mit $\leq 4$ Zellen/ $\mu$ l [Lymphozyten: 92\% (72\%/94\%) versus 77.5\% (67\%/87.75\%), Median (25./75. Perzentile) (Mann-Whitney U-Test: p<0.01); Granulozyten: 19\% (2\%/31\%) versus 3.5\%( 0\%/8.25\%) (Mann-Whitney U-Test: $\mathrm{p}=0.013)$. Umgekehrt traten Monozyten in Liquorproben mit einer Pleozytose seltener auf als bei Proben mit einer normalen Liquor-Zellzahl [8\% (6\%/14\%) versus 12\% (10\%/20\%) $(\mathrm{p}<0.009)]$.

\subsubsection{Laktatveränderungen im Liquor}

Das Laktat im Liquor war bei 65,2 \% erhöht (> 2,4 mmol/l). Bei 66 von 132 Patienten (50\%) kam es sogar zu einer Erhöhung von mehr als 3,5 mmol/l. Außerdem konnte gezeigt werden, dass die Laktatkonzentration im Liquor mit der Zellzahl im Liquor korreliert. 


\section{Diagramm 3: Korrelation Laktatkonzentration/ Zellzahl im Liquor}

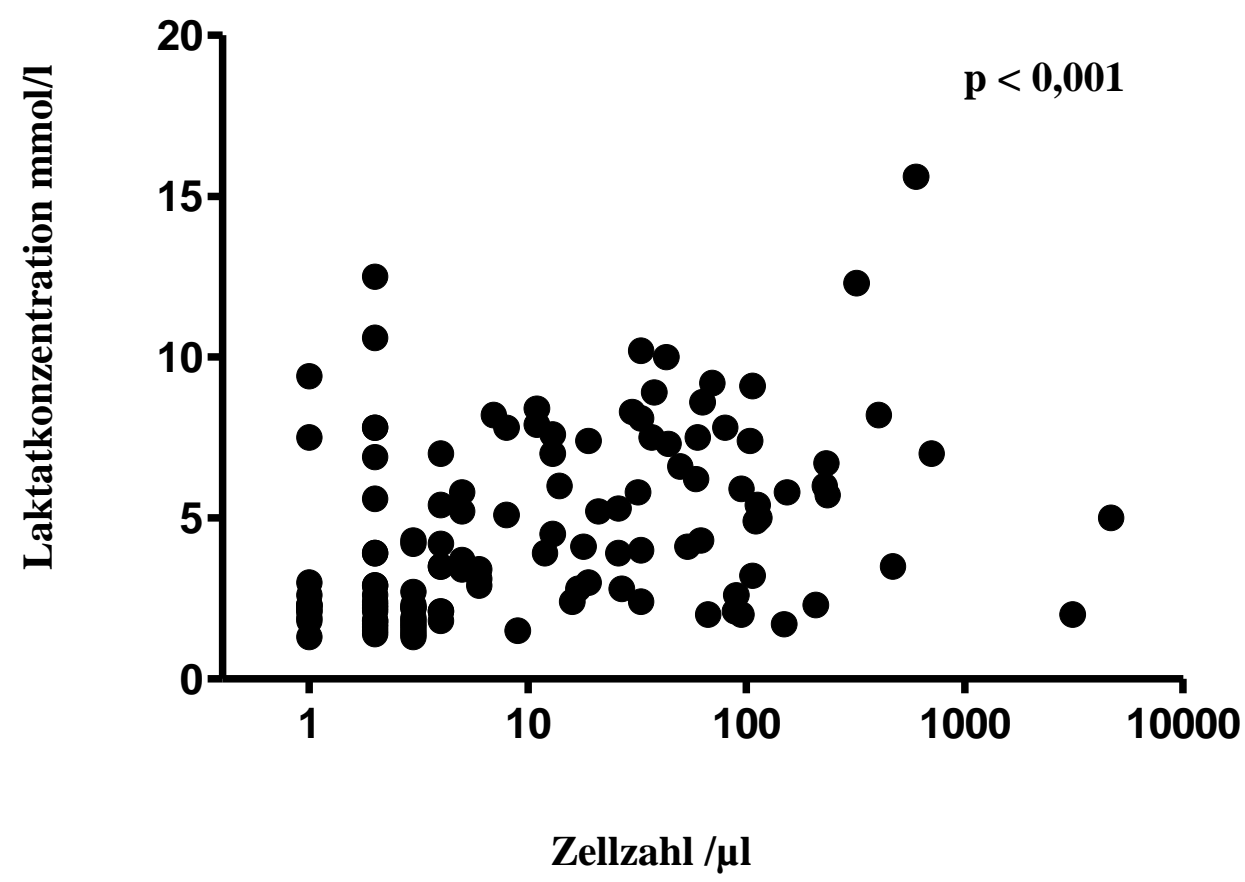

Diagramm 3: Durch die Berechnung mit dem Spearman's Rankkorrelationkoeffizienten konnte gezeigt werden, dass die Liquorlaktatkonzentration $(\mathrm{n}=132)$ mit der Zellzahl korreliert $(\mathrm{rS}=0.42, \mathrm{p}<0.001)$.

\subsubsection{Gesamtprotein/ Schrankenstörungen}

Das Gesamtprotein war in 102 von 130 Fällen (78,5\%) erhöht (> 450mg/dl). Die Spannweite des Nachweises des Gesamtproteins reicht von 166 bis $15840 \mathrm{mg} / 1$ (min, max) (median: $1012 \mathrm{mg} / \mathrm{l})$. Auch in diesem Fall konnte mit Hilfe des Spearman's Rankkorrelationkoeffizienten nachgewiesen werden, dass es eine Korrelation zwischen dem Gesamtprotein im Liquor und der Zellzahl gab (Diagramm 4). 


\section{Diagramm 4: Korrelation Gesamtprotein/Zellzahl im Liquor}

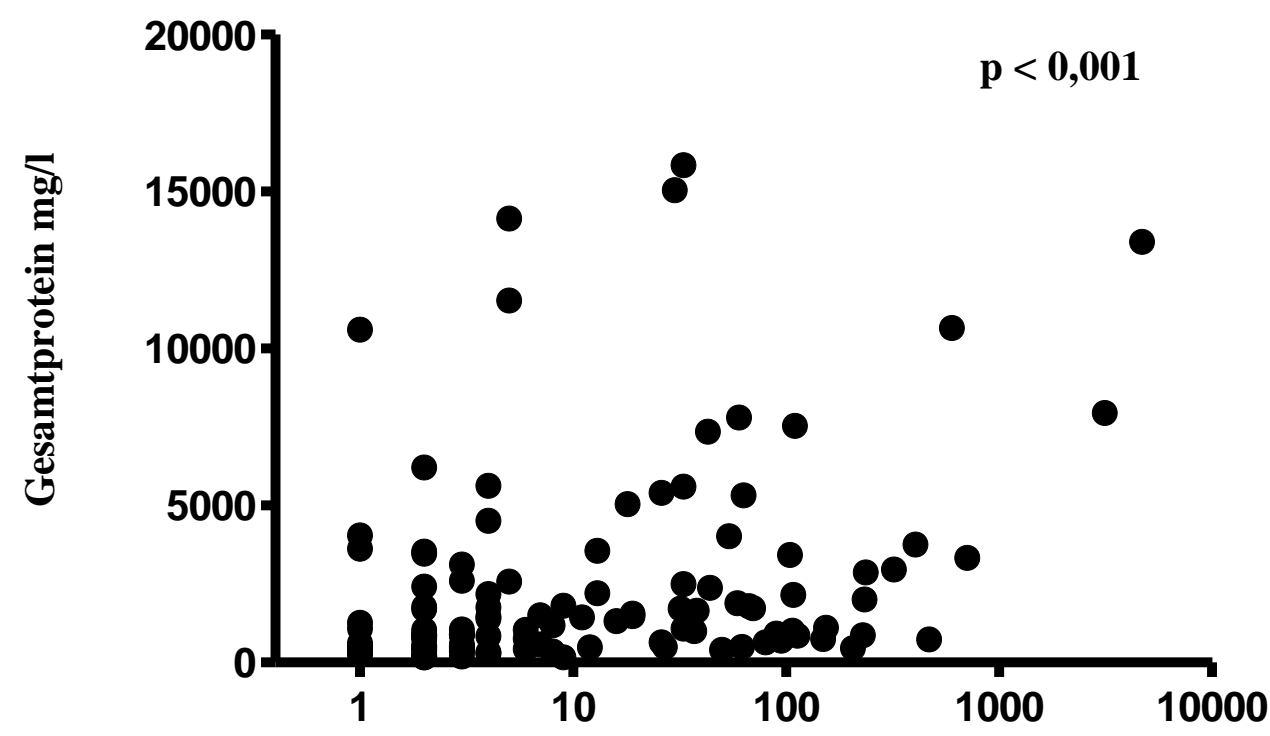

\section{Zellzahl $/ \mu \mathrm{l}$}

Diagramm 4: Durch die Berechnung mit dem Spearman's Rangkorrelationkoeffizienten konnte eine Korrelation zwischen dem Gesamtprotein und der Zellzahl im Liquor nachgewiesen werden ( $\mathrm{n}=130, \mathrm{rS}=$ $0.45, \mathrm{p}<0.001)$.

Bei 84 von 121 Patienten (69,4\%) kam es zu einer Schrankenfunktionsstörung, die im Rahmen der Meningeosis neoplastica aufgetreten ist.

\subsubsection{Ferritin-/CEA-Bestimmung im Liquor}

Im Rahmen der Diagnostik wurden bei 81 von 132 Patienten (61,4\%) das CEA mitbestimmt. Bei 25 von diesen 81 Patienten kam es zu einem Nachweis einer intrathekalen CEA-Synthese (30.9\%). Bei keinem Patienten mit einer Meningeosis lymphomatosa konnte eine intrathekale CEA-Synthese nachgewiesen werden. Im Vergleich dazu konnte bei 25 von 65 Patienten (38,5\%), bei denen eine Meningeosis neoplastica vorlag, eine intrathekale CEA-Synthese gezeigt werden.

Weitere Tumormarker, wie bereits oben genannt (Unterpunkt 1.3.), wurden in diesem Patientenkollektiv in der Diagnostik nicht mitbestimmt.

Der Ferritinwert wurde bei insgesamt 118 Patienten (89,4\%) im Rahmen der Diagnostik mitbestimmt. Es kam bei insgesamt 56 von 118 Patienten (47,5\%) zu einer Erhöhung des Ferritinwertes im Liquor. 


\subsubsection{Intrathekale Synthese von Ig-Antikörpern}

Eine intrathekale Synthese von IgG, IgA oder IgM-Antikörpern konnte anhand der ReiberFelgenhauer-Diagramme bei 13 Patienten beobachtet werden. Bei 4 Patienten zeigte sich eine intrathekale Synthese von IgG. Es kam bei zwei Patienten zu einer IgA-Synthese und bei 9 Patienten zu einer IgM-Synthese. Bei zwei weiteren Patienten erfolgte der Nachweis von mehr als einer Antikörper-Klasse im Rahmen der Liquoranalyse durch die Nephelometrie (ein Patient IgG plus IgM; ein Patient IgG plus IgA).

Durch die Durchführung der isoelektrischen Fokussierung konnte bei 25 von 62 Patienten eine intrathekale IgG-Synthese nachgewiesen werden, was wiederum bedeutet, dass die isoelektrische Fokussierung sensitiver als die Nephelometrie war.

\subsubsection{CT-/MRT-Befunde}

Insgesamt 97 Patienten [cCT $(n=19)$, cMRT $(n=24)$ oder beides $(n=54)]$ haben im Rahmen der Diagnostik eine Bildgebung erhalten. Bei der der Bildgebung handelte es sich entweder um die Computertomographie oder um die Magnetresonanztomographie.

Bei 50 Patienten (51,5\%) gelang durch die Bildgebung der Nachweis einer Meningeosis neoplastica. 


\section{$4 \quad$ Diskussion}

Die Lumbalpunktion inklusive der Auswertung der Liquorparameter ist ein entscheidender Bestandteil in der Diagnostik der Meningeosis neoplastica. Bereits durch die erste Punktion können ca. 50\% der Patienten, die an einer Meningeosis neoplastica erkrankt sind, als solche identifiziert werden (Herrlinger et al. 2008).

Im Rahmen der Auswertung wurden nur Patienten berücksichtigt, bei denen Tumorzellen nachgewiesen werden konnten.

Der Nachweis von malignen Zellen im Liquor ist ein wichtiges Kriterium für die Diagnose Meningeosis neoplastica und konnte auch schon in anderen Studien nachgewiesen werden (Liu et al. 2009).

Ein besonderes Augenmerk sollte bei der Auswertung im Rahmen dieser Studie jedoch vor allem auf dem Liquorlaktat liegen, denn unter physiologischen Bedingungen ist die Konzentration des Laktats im Liquor unabhängig von der Serumkonzentration und wird in Kompartimenten des zentralen Nervensystems produziert.

Vor allem Neurone und Leukozyten sind durch eine anaerobe Glykolyse verantwortlich für die Produktion des Liquorlaktats (Wellmer et al. 2001). Eine Erhöhung des Laktats im Liquor ist jedoch nicht spezifisch für eine bestimmte Krankheit (Reiber 2006c). Neben Erkrankungen wie dem Morbus Alzheimer (Parnetti et al. 1995), einem ischämischen Schlaganfall (Brouns et al. 2008), einer Meningeosis neoplastica (Hornig et al. 1983) und mitochondrialen Erkrankungen, die neuropsychiatrische Symptome aufweisen (Finsterer 2001), kommt es auch im Rahmen von bakteriellen Meningitiden zu einer Erhöhung des Liquorlaktates. Jedoch stammt das Liquorlaktat bei einer bakteriellen Meningitis zu mehr als $95 \%$ von dem Wirt selber und nicht von den Bakterien im Liquor (Wellmer et al. 2001).

Ein wichtiger Punkt ist jedoch auch, dass die Laktatkonzentration im Liquor bei Patienten ohne Entzündungen im ZNS signifikant mit dem Alter der Patienten korreliert (Lehmnitz et al. 2005, Djukic et al. 2012). Aus diesem Grund muss sich bewusstgemacht werden, dass eine Erhöhung der Laktatkonzentration im Alter per se nicht immer als pathologisch eingestuft werden sollte, sondern einer ausführlichen Abklärung und einer Beurteilung der Symptome des Patienten und ggf. weiterer Diagnostik bedarf. Hintergrund der höheren Laktatkonzentration im höheren Alter ist häufig, dass die Patienten multimorbide sind und somit ein gesteigerter anaerober Metabolismus in den Kompartimenten des ZNS vermutet werden kann (Djukic et al. 2013). 
Im Rahmen unserer Untersuchungen konnten wir zeigen, dass es bei 86 von 132 Patienten $(65,1 \%)$ zu einer Erhöhung des Laktats im Rahmen dieser Erkrankung kam. Dieses Ergebnis ist somit übereinstimmend mit vorherigen Studien, in denen nachgewiesen werden konnte, dass es zu einer Erhöhung des Liquorlaktatwertes im Rahmen einer Meningeosis neoplastica kommen kann (Wasserstrom et al. 1982, van Zanten et al 1986, Hau 2015).

Im Rahmen einer genaueren Betrachtung zeigte sich, dass es bei insgesamt 66 von den oben genannten 86 Patienten (76,7\%), bei denen eine Erhöhung des Laktatwertes gezeigt werden konnte, zu einem deutlichen Anstieg mit Werten über 3,5 mmol/1 kam.

Im klinischen Alltag liegt in der Liquordiagnostik der Cut-off-Wert für das Laktat bei 2,4 $\mathrm{mmol} / \mathrm{l}$ und hilft somit insbesondere in der differentialdiagnostischen Abgrenzung zu anderen Erkrankungen. Vor allem bei bakteriellen Meningitiden (Kleine et al. 1979) und im Rahmen einer tuberkulösen Meningitis (Prange et al. 2004) kommt es in knapp 90\% der Fälle zu einem Anstieg des Liquorlaktates über 3,5 mmol/1.

Insbesondere für die Differenzierung zwischen einer bakteriellen und viralen Meningitis eignet sich ein Cut-off-Wert von 3,5 mmol/l (Giulieri et al. 2015).

Bei einer HIV-Erkrankung kann es zu chronischen Meningitiden kommen. Auch hier zeigt sich, dass es zu einem Anstieg des Liquorlaktatwertes von über 3,5 mmol/l kommen kann, sodass dieser höhere Cut-off-Wert gerade für die Differenzierung zwischen einer Kryktokokkenmeningitis, einer tuberkulösen Meningitis und einer Meningitis im Rahmen einer HIV-Erkrankung genutzt werden kann (de Almeida et al. 2011).

Im Rahmen einer akuten Lyme-Neuroborreliose, wobei es sich um eine bakterielle Infektion des ZNS handelt und einer Meningeosis neoplastica sehr ähnlich sein kann (radikuläre Symptome, Hirnnervenparesen), zeigten nur 5 von 118 Patienten (4\%) einen Laktatwert im Liquor von $\geq 3.5 \mathrm{mmol} / 1$ (Djukic et al. 2012).

Das bedeutet, dass Liquorlaktatkonzentrationen $\geq 3.5 \mathrm{mmol} / 1$ zur Differenzierung einer Meningeosis neoplastica von einer viralen Meningitis, Encephalitis und Neuroborreliose genutzt werden können, jedoch nicht für die Differenzierung einer Neurotuberkulose, HIVoder einer Pilz-Meningoenzephalitis.

Neben der Erhöhung der Laktatkonzentration im Liquor, kann es im Rahmen der Meningeosis neoplastica und den damit möglichen entzündlichen Begleiterscheinungen zu einem Anstieg der Zellzahl im Liquor von mehr als 4 Zellen/ $\mu$ l kommen (Liu et al. 2009).

Überraschenderweise hatten 50\% der Liquorproben eine normale Zellzahl. In einer vorangegangenen Studie hatten 32\% der Patienten mit einer zytologisch nachgewiesenen Meningeosis neoplastica eine normale Zellzahl (Liu et al. 2009). Beide Studien zeigen, dass 
sich Kliniker nicht auf eine normale Zellzahl berufen sollten, um eine Meningeosis neoplastica auszuschließen, sodass eine sorgfältige zytologische Analyse aller Liquorproben notwendig ist, wenn eine Infiltration des Liquors durch bösartige Zellen vermutet wird.

Die Meningeosis neoplastica ist häufig mit einer inflammatorischen Reaktion verbunden. Sowohl das Vorkommen einer intrathekalen IgG-, IgA- und IgM-Synthese als auch die hohe Anzahl von Lymphozyten in den Liquorproben der Patienten mit einer Meningeosis neoplastica induzieren eine Involvierung des erworbenen Immunsystems. Ähnlich wie bei der Neuroborreliose war die isoelektrische Fokussierung sensitiver, eine intrathekale IgGSynthese nachzuweisen, als das Reiber-Felgenhauer-Diagramm (Djukic et al. 2012).

Das Auftreten von Granulozyten im Liquor ist hinweisend auf die Beteiligung des angeborenen Immunsystems in der Antwort des Immunsystems auf die entzündliche Reaktion. Bei der tuberkulösen Meningitis, die sich ebenfalls sowohl durch eine starke Erhöhung der Laktat-, Gesamtproteinkonzentration als auch der Zellzahl (10-500 Zellen/ $\mu$ l) im Liquor auszeichnet, war das Vorkommen von neutrophilen Granulozyten (> 50\%) (Thwaites et al. 2002) ein starker Prädiktor für die tuberkulöse Meningitis mit einer Sensitivität von 54\% und einer Spezifität von 98\% (Zou et al. 2015).

Der Granulozytenanteil war bei nur zwei der 55 Liquoproben, bei denen eine Zelldifferenzierung in unserer Studie durchgeführt wurde, mehr als $50 \%$, sodass beim vermehrten Vorkommen von neutrophilen Granulozyten die Diagnose einer Meningeosis neoplastica unwahrscheinlich erscheint.

Da jedoch auch bei knapp 50\% der Patienten, bei denen eine tuberkulöse Meningitis diagnostiziert wurde, kein vermehrtes Auftreten von neutrophilen Granulozyten nachzuweisen ist (Thwaites et al. 2002), sollte bei der Differenzierung der beiden Erkrankungen sowohl eine bakteriologische Untersuchung (Ziehl-Neelsen-Färbung,

Kulturen, Polymerasekettenreaktion) als auch eine zytologische Identifizierung von Tumorzellen durchgeführt werden.

Bei 102 von 130 Patienten (78,5\%) kam es zu einem Anstieg des Gesamtproteins im Liquor.

Das Gesamtprotein stellt somit - neben dem Nachweis von Tumorzellen - einen der sensitivsten Indikatoren für die Diagnose einer Meningeosis neoplastica dar (Glass et al. 1979). Das gehäufte Auftreten vom Anstieg des Gesamtproteins in dieser Studie deckt sich auch mit den Ergebnissen aus anderen Studien (Glass et al. 1979, Bruna et al. 2009).

Bei 81 Patienten wurde der CEA-Wert mitbestimmt. Jedoch kann man bei Patienten, die einen CEA- produzierenden Tumor haben, die Diffusion von CEA-Molekülen über die BlutLiquor- und auch die Blut-Hirn-Schranke nicht vernachlässigen. Die CEA-Konzentration im 
Liquor ist abhängig von der entsprechenden Konzentration im Blutserum und auch absolute Cut-off-Werte sind nicht zuverlässig. Aufgrund der gleichen Molekülmasse von CEA und IgA kann man das Reiber-Felgenhauer-Diagramm für den Nachweis von einer intrathekalen CEA-Synthese hinzuziehen (DGN 2014, Petereit et al. 2007, Reiber 2016). In 25 von 65 Fällen (38,5\%), bei denen eine Meningeosis neoplastica vorlag, war das Reiber-FelgenhauerDiagramm hinweisend auf eine intrathekale CEA-Synthese. Der Nachweis von intrathekalem CEA durch die Benutzung des IgA-Diagramms ist zwar ein sehr spezifischer, jedoch kein sehr sensitiver Marker für die Meningeosis neoplastica oder zerebrale Metastasen.

Eine weitere Methode für den Nachweis einer intrathekalen CEA-Synthese ist der Vergleich des CEA-Liquor/Blut-Quotienten und des Albumin-Liquor/Blut-Quotienten. Eine intrathekale CEA-Synthese kann vermutet werden, wenn der CEA- Liquor/Blut-Quotient am gleichen Tag größer ist als der Albumin-Liquor/Blut-Quotient. Jedoch ist aufgrund der größeren Molekülmasse des CEA diese Methode weniger sensitiv als die Nutzung des IgADiagrammes im Reiber-Felgenhauer-Diagramm (DGLN 2014).

Aus diesem Grund bezweifeln wir, dass das Vorkommen von CEA-Konzentrationen im Liquor, ohne Kenntnis der entsprechenden Serumkonzentration, einen großen Nutzen in Nachweis einer Meningeosis neoplastica besitzen. Jedoch wurde auch berichtet, dass der CEA-Wert in Verbindung mit der Bestimmung von NSE und CYFRA21-1, ohne die Kenntnis der entsprechenden Serumwerte, von großem Nutzen in der Diagnostik der Meningeosis neoplastica im Rahmen eines Lungenkarzinoms sein kann (Wang et al. 2013). Insgesamt wurde bei 56 von 118 Patienten (47,5\%) ein erhöhter Ferritinwert im Liquor festgestellt. Dass es im Rahmen von neoplastischen und meningitischen ZNS-Erkrankungen zu einer Erhöhung des Ferritinwertes kommen kann, ist bereits in anderen Studien belegt worden (Kolodziej et al. 2014). Jedoch ist die Bandbreite der Erkrankungen, bei der es zu einer Erhöhung des Ferritins kommen kann, relativ hoch, sodass eine Zuordnung zu genau einer Erkrankung erschwert ist und somit auch nicht als einziges diagnostisches Mittel bestimmt werden sollte (Kolodziej et al. 2014).

Einhergehend mit der Auswertung der Vorerkrankungen unserer Patienten stellte sich heraus, dass die häufigsten primären Tumoren, wie sie auch in anderen Studien beschrieben worden sind (Herrlinger et al. 2008, Bruna et al. 2009), das Mammakarzinom (32,6\%) sowie das Lungenkarzinom $(25,0 \%)$ sind.

In unserer Gruppe zeigte sich in der weiteren Auswertung jedoch eine kleine Abweichung zu den in der Literatur beschrieben häufigsten primären Tumoren nach dem Mamma- und 
Lungenkarzinom. Am dritthäufigsten waren bei uns die hämatologischen Erkrankungen $(21,2 \%)$, gefolgt von den gastrointestinalen Tumoren (8,3\%). Die Melanome, die in der Literatur (Wasserstrom et al. 1982) mit als häufigster primärer Tumor nach Mamma- und Lungenkarzinom beschrieben werden, machten im Rahmen unserer Auswertung nur einen kleinen Anteil aus (3,8\%).

Initial stellten sich Patienten mit unterschiedlichsten neurologischen und vegetativen Symptomen vor. Die klinischen Symptome lassen sich in drei ursprüngliche Säulen einteilen. Die drei Säulen umfassen zum einen die zerebrale Schädigung im Bereich des Großhirnes, als auch die Schädigung im Bereich des Hirnstammes und der Hirnnerven sowie als letzte Säule die spinale Schädigung.

Bei insgesamt 64 von 132 Patienten (48,8\%) zeigten sich im Rahmen der Aufnahmeuntersuchung radikuläre Symptome. Radikuläre Symptome, die durch die Infiltration der Spinalwurzeln auftreten, sind neben den Hirnnervenparesen die mit am häufigsten Symptome bei der Meningeosis neoplastica auftreten und auch in anderen Untersuchungen beschrieben wurden (Bruna et al. 2009, Le Rhun et al. 2013).

Bei genauerer Betrachtung zeigte sich bei 27 von den 66 oben genannten Patienten (40,9\%) eine radikuläre Symptomatik im Bereich der unteren Extremitäten, die vor allem die motorischen Äste betraf, wobei wiederum bei 17 von diesen Patienten eine Querschnittssymptomatik weiter beschrieben wurde. Vergleichbare genaue Ergebnisse zum Bereich radikuläre Symptome wie in dieser Studie sind in anderen aktuellen Studien nicht zu finden, da dort die primären Symptome eher allgemein beschrieben worden sind.

55 Patienten unseres Patientenkollektives $(41,6 \%)$ zeigten in der neurologischen Untersuchung Symptome einer Hirnnervenparese.

Am häufigsten konnte in diesem Patientenkollektiv eine Fazialisparese (15 von 55 Patienten, 27,3\%) diagnostiziert werden, was ein ähnliches Ergebnis wie in anderen Studien ist (Bruna et al. 2009, Le Rhun et al. 2013).

Die Hirnnervenparesen machen auch in anderen Studien das häufigste primäre Symptom aus, das als Folge der Erkrankung an der Meningeosis neoplastica anzusehen ist (Wasserstrom et al. 1982, Bruna et al. 2009).

Bei 43 Patienten konnten in der initialen Aufnahmeuntersuchung entweder durch die Eigenanamnese oder fremdanamnestisch psychologische Veränderungen bzw. Auffälligkeiten nachgewiesen werden.

Die von uns beschriebenen psychischen Symptomen sind in der bisherigen Literatur nur am Rande erwähnt worden (Le Rhun et al. 2013). 
Darauffolgend waren am häufigsten Cephalgien, sowie Übelkeit und Erbrechen, wobei diese Symptome hinweisend auf eine Hirndrucksymptomatik sein können, die durch den verminderten Abfluss des Liquors entsteht, wenn sich die Zellen der Meningeosis neoplastica in dem Bereich der Pacchioni-Granulationen ablagern (Herrlinger et al. 2008). 


\section{Zusammenfassung}

Die Meningeosis neoplastica ist eine meningeale Karzinose, die am häufigsten im Rahmen von Mammakarzinomen und Lungenkarzinomen auftritt. Dort macht sie eine häufig gefürchtete Spätkomplikation aus, die aufgrund der späten Diagnose oder des späten Auftretens nur noch eine geringe Überlebenschance mit sich bringt.

Überraschenderweise waren die Hauttumoren, die nach Mamma- oder Lungenkarzinomen am häufigsten eine Meningeosis neoplastica als Folge haben können, in diesem Patientenkollektiv am seltensten vertreten.

Als Diagnostikum werden zum einen sowohl die Liquorpunktion mit anschließender Analyse des Liquors sowie das klinische Erscheinungsbild des/der Patient/in, als auch bildgebende Verfahren, wie das cMRT und cCT, hinzugezogen.

Im Vordergrund steht bei der Analyse des Liquors der Patienten mit Verdacht auf eine Meningeosis neoplastica die Zytologie, die den Nachweis von Tumorzellen im Liquorsediment beinhaltet. Die Bestimmung vom Gesamtprotein, der Glukose, des Laktats und der Zellzahl im Liquor ist aber ebenfalls ein obligater Bestandteil des diagnostischen Verfahrens.

Als sensitivster, aber wenig spezifischer Marker wird das Gesamtprotein betrachtet, jedoch kommt es bei der Meningeosis neoplastica auch häufig zu einer Abnahme der Glukose bei gleichzeitigem Anstieg des Laktats im Liquor.

Ein Anstieg des Liquorlaktates kann aber auch im Rahmen anderer Erkrankungen, wie z.B. der bakteriellen Meningitis, der tuberkulösen Meningitis, auftreten, sodass ein Laktatanstieg im Liquor immer im Gesamtbild mit dem klinischen Erscheinungsbild betrachtet werden sollte.

Die Meningeosis neoplastica bietet häufig ein buntes Bild an klinisch sichtbaren Manifestationen, die häufig zu einer starken Einschränkung im Leben des Patienten führt. Die Diagnostik der Erkrankung anhand der Liquorpunktion sowie die Analyse des Liquors sollte in den Fokus aktueller Studien gestellt werden, um zum einen eine frühestmögliche Diagnose anhand der bestimmten Parameter stellen zu können und zum anderen die Differenzierung gegenüber anderen entzündlichen Erkrankungen im ZNS zu verbessern. Die vorliegende retrospektive Studie nimmt Bezug auf diese Problematik.

Anhand eines Kollektivs von 132 Patienten, die sich zwischen 2001 und 2012 aufgrund verschiedener Symptomatik in der Universitätsklinik Göttingen, im Evangelischen Krankenhaus Weende sowie umliegenden Krankenhäusern vorstellten, konnte gezeigt 
werden, dass es im Rahmen der Meningeosis neoplastica zu einer Veränderung verschiedenster Parameter im Liquor kommt.

Bei insgesamt 86 von 132 Patienten zeigten sich Laktatkonzentrationen im Liquor, die deutlich über dem altersabhängigen Normwert lagen. Von den genannten 86 Patienten hatten wiederum 66 Patienten deutlich gesteigerte Laktatkonzentrationen, die einen Wert von $3,5 \mathrm{mmol} / 1$ deutlich überstiegen.

Somit kommt es im Vergleich zu anderen Erkrankungen, wie z.B. der tuberkulösen Meningitis, bei der knapp 90\% der Erkrankten Laktatkonzentrationen von mehr als 3,5 mmol/l im Liquor haben, bei der Meningeosis neoplastica auch zu einem Anstieg des Laktats, jedoch nicht so fulminant wie bei anderen entzündlichen Erkrankungen im ZNS. Deshalb sollte die Diagnose nicht nur anhand des Liquorlaktatwertes, sondern sowohl im Einklang mit der vorhandenen Klinik, die der Patient zeigt, als auch durch unterstützende Bildgebung (z.B. MRT) gestellt werden.

Neben dem Anstieg der Laktatkonzentration kam es bei 50\% der Patienten zu einer Zunahme der Zellzahl im Liquor. Bei den anderen 50\% war trotz zytologischem Nachweis einer Meningeosis neoplastica die Liquorzellzahl normal.

Des Weiteren kam es bei 78,5\% der Patienten zu einem Anstieg des Gesamtproteins.

Im Rahmen dieser Arbeit konnte eine Korrelation ( $\mathrm{rS}=0.42, \mathrm{p}<0.001$ ) zwischen Liquorzellzahlerhöhung und Liquorlaktaterhöhung festgestellt werden.

Am häufigsten zeigten die Patienten bei der initialen Aufnahme Ausfälle im Bereich der Hirnnerven oder beklagten neben psychologischen Symptomen häufig radikuläre Ausfälle im Bereich der unteren Extremität, v. a. das motorische System betreffend. Wie bereits oben genannt, waren auch in dieser Studie das Mammakarzinom mit knapp 32,6\% sowie das Lungenkarzinom mit knapp 25,0\% die häufigsten Grunderkrankungen im gesamten Patientenkollektiv.

Die Lumbalpunktion stellt gerade in Hinsicht auf die Diagnostik der Meningeosis neoplastica ein wichtiges und schnelles Hilfsmittel dar, da es sich dabei um ein minimalinvasives, komplikationsarmes Verfahren handelt, das auch finanziell tragbar ist. Deswegen sollte bei jedem Patienten mit einer der oben genannten Erkrankungen in seiner Vorgeschichte und dem neu auftretenden oben genannten klinischen Erscheinungsbild eine Lumbalpunktion im Rahmen der Diagnostik durchgeführt werden.

Weitere Studien und Untersuchungen in Bezug auf Veränderungen der Liquorparameter sowie der klinischen Manifestation bei der Meningeosis neoplastica werden vonnöten sein, 
um in Zukunft eine noch schnellere sowie effektivere Diagnosestellung gewährleisten zu können. 


\section{$6 \quad$ Literaturverzeichnis}

Brouns R, Sheorajpanday R, Wauters A, De Surgeloose D, Mariën P, De Deyn PP (2008): Evaluation of lactate as a marker of metabolic stress and cause of secondary damage in acute ischemic stroke or TIA. Clin Chim Acta $\underline{397}, 27-31$

Bruna J, Gonzalez L, Miro J, Velasco R, Gil M, Tortosa A; Neuro-Oncology Unit of the institute of Biomedical Investigation of Belvitge (2009): Leptomeningeal Carcinomatosis, Prognostic Implications of Clinical and Cerebrospinal Fluid Features. Cancer 115, 381-389

Chamberlain MC (1997): Carcinomatous meningitis. Arch Neurol $\underline{54}$, 16-17

Chamberlain MC, Nolan C, Abrey LE (2005): Leukemic and lymphomatous meningitis: incidence, prognosis and treatment. J Neuro Oncol $\underline{75}, 71-83$

Conly JM, Ronald AR (1983): Cerebrospinal fluid as a diagnostic body fluid. Am J Med $\underline{75}$, $102-107$

Davson H, Segal MB: Physiology of the CSF and blood-brain barriers. CRC Press, Boca Raton 1996

de Almeida SM, Boritza K, Cogo LL, Pessa L, França J, Rota I, Muro M, Ribeiro C, Raboni SM, Vidal LR, Nogueira MB, Ellis R. (2011): Quantification of cerebrospinal fluid lactic acid in the differential diagnosis between HIV chronic meningitis and opportunistic meningitis. Clin Chem Lab Med 49, 891-896

DGLN: Deutsche Gesellschaft für Liquordiagnostik und Klinische Neurochemie(Hrsg.): Ausgewählte Methoden der Liquordiagnostik und klinischen Neurochemie. Bearb. Von Wick M. 3. Auflage; o. Verl., München 2014 
DGN: Deutsche Gesellschaft für Neurologie (Hrsg.): Leitlinien für Diagnostik und

Therapie in der Neurologie - Leitlinie Metastasen und Meningeosis neoplastica. Stand: 01.

März 2014.

https://www.dgn.org/images/red_leitlinien/LL_2014/PDFs_Download/030060_LL_Hir nmetastasen_und_Meningeosis_neoplastica_final.pds (besucht am 15. Dezember 2016)

Diener H-C, Weimer C: Leitlinien für Diagnostik und Therapie in der Neurologie. Herausgegeben von der Kommission „Leitlinien“ der Deutschen Gesellschaft für Neurologie. 5., vollständig überarb. Auflage; Georg Thieme Verlag, Stuttgart 2012

Djukic M, Schmidt-Samoa C, Lange P, Spreer A, Neubieser K, Eiffert H, Nau R, Schmidt H (2012): Cerebrospinal fluid findings in adults with acute Lyme neuroborreliosis. J Neurol $\underline{259}, 630-636$

Djukic M, Schulz D, Schmidt H, Lange P, Nau R (2013): Cerebrospinal fluid findings in geriatric patients from 2008 to 2011. Z Gerontol Geriatr 46, 353-357

Eberth CJ (1870): Zur Entwicklung des Epitheliomas (Cholesteatomas) der Pia und der Lunge. Virchow's Arch $\underline{49}, 51-63$

Finsterer J (2001): Cerebrospinal-fluid lactate in adult mitochondriopathy with and without encephalopathy. Acta Med Austriaca 28, 152-155

Garcia T, Killian JA, De Sanctis A (1928): The lactic acid and the sugar content of the spinal fluid in meningitis. Arch Pathol $\underline{6}, 530$

Giulieri S, Chapuis-Taillard C, Jaton K, Cometta A, Chuard C, Hugli O, Du Pasquier R, Bille J, Meylan P, Manuel O, Marchetti O (2015): CSF lactate for accurate diagnosis of community-acquired bacterial meningitis. Eur J Clin Microbiol Infect Dis $\underline{34}$, 2049-2055 
Glass JP, Melamed M, Chernik NL, Posner JB (1979): Malignant cells in cerebrospinal fluid (CSF): The meaning of a positive CSF cytology. Neurology 29, 1369-1375

Grossman SA, Krabak US (1999): Leptomeningeal carcinomatosis. Cancer Treat Rev $\underline{25}$, 103-109

Gröschel K, Schnaudigel S, Pilgram S.M, Wasser K, Kastrup A (2008): Die diagnostische Lumbalpunktion. Dtsch Med Wochenschr 133, 39-41

Hau P, Pukrop T (2015): Lebenszeit verlängern und Symptome von Hirnmetastasen lindern. InFo Neurologie\& Psychiatrie 17, 44-56

Herrlinger U, Förschler H, Küker W, Meyermann R, Bamberg M, Dichgans J, Weller M (2004): Leptomeningeal metastasis: survival and prognostic factors in 155 patients. J Neurol Sci $\underline{223}, 167-178$

Herrlinger U, Astner S, Thiel E (2008): Meningeosis neoplastica im Rahmen einer ZNS Metastasierung. Onkolge 14, 267-273

Hoffmann JJ, Janssen WC (2002): Automated counting of cells in cerebrospinal fluid using the CellDyn-4000 maematology analyser. Clin Chem Lab Med 40, 1168-1173

Hornig CR, Busse O, Kaps M (1983): Importance of cerebrospinal fluid lactate determination in neurological diseases. Klin Wochenschr $\underline{61}$, 357-361

Jaeckle KA (2006): Neoplastic meningitis from systemic malignancies: diagnosis, prognosis and treatment. Semin Oncol $\underline{33}, 312-323$ 
Kaplan JG, DeSouza TG, Farkash A, Shafran B, Pack D, Rehman F, Fuks J, Portenoy R. (1990): Leptomeningeal metastases: comparison of clinical features and laboratory data of solid tumors, lymphomas and leukemias. J Neurooncol $\underline{9}$, 225-229

Killian JA (1925): Sugar and lactic acid of spinal fluid in meningitis. Proc Soc Exper Biol Med $\underline{23}, 255$

Kleine TO, Baehrlocher K, Niederer V, Keller H, Teuter F, Tritschler W, Bablock W. (1979): Die diagnostische Bedeutung der Lactatbestimmung im Liquor bei Meningitis. Dtsch Med Wochenschr 104, 553-557

Kleine TO: Lactat. In: Zettl UK, Lehmitz R, Mix E (Hrsg.): Klinische Liquordiagnostik. 2. Auflage; de Gruyter, Berlin 2005, 130-133

Kölmel H-W. Liquorzytologie. In: Zettl UK, Lehmnitz R, Mix E (Hrsg.): Klinische Liquordiagnostik. 2. Auflage; de Gruyter, Berlin 2005, 135-159

Kolodziej MA, Proemmel P, Quint K, Strik HM (2014): Cerebrospinal fluid ferritin unspecific and unsuitable for disease monitoring. Neurol Neurochir Pol 48, 116-121

Lehmnitz R, Hobusch D, Kluge H, Mix E, Zettl UK: Referenzwerte für Liquorparameter mit diagnostischer Relevanz. In: Zettl U, Lehmnitz R, Mix E (Hrsg.): Klinische Liquordiagnostik. 2. Aufalge; de Gruyter, Berlin 2005, 88-94

Le Rhun E, Sophie T, Chamberlain M (2013): Carcinomatous meningitis: Leptomeningeal metastases in solid tumors. Surg Neurol Int $\underline{4}, 265-288$

Liu J, Jia H, Yang Y, Dai W, Su X, Zhao G (2009): Cerebrospinal fluid cytology and clinical analysis of 34 cases with leptomeningeal carcinomatosis. J Int Med Res $\underline{37}, 1913-1920$ 
Luft D, Götz R (1983): Lactat im Liquor cerebrospinalis. Bedeutung für

Differentialdiagnose, Therapiekontrolle und Prognose zerebraler und meningealer Erkrankungen. Lab Med 7, 55-59

Masuhr KF, Neumann M: Duale Reihe Neurologie. 6. Auflage; Georg Thieme Verlag, Stuttgart 2007

Mayor A (2015): Artefakte in der Computertomografie. Radiopraxis $\underline{8}, 145-160$

Ohnoshi T, Ueoka H, Kiura K Mima Y, Miyatake K, Genba K, Matsumura T, Chikamori M, Hiraki S, Kimura I (1993): [Meningeal carcinomatosis in patients with small cell lung cancer] [Artikel in japanischer Sprache]. Nihon Kyobu Shikkan Gakkai Zasshi 31, 324-329

Oschmann P, Kunesch E, Zettl UK. Liquorpunktion- Indikationen, Techniken und Komplikationen. In: Zettl UK, Lehmnitz R, Mix E (Hrsg.) Klinische Liquordiagnostik. 2. Auflage; de Gruyter, Berlin 2005, 21-38

Parnetti L, Gaiti A, Polidori MC, Brunetti M, Palumbo B, Chionne F, Cadini D, Cecchetti R, Senin U (1995): Increased cerebrospinal fluid pyruvate levels in Alzheimer's disease. Neurosci Lett $\underline{199}, 231-233$

Pentheroudakis G, Pavlides N (2005): Management of leptomeningeal malignancy. Expert Opin Pharmacother $\underline{6}, 1115-1125$

Petereit H-F, Sindern E, Wick M (Hrsg.): Leitlinien der Liquordiagnostik und Methodenkatalog der Deutschen Gesellschaft für Liquordiagnostik und Klinische Neurochemie. Springer Medizin Verlag, Heidelberg 2007

Posner JB, Plum F (1967): Independence of blood and CSF lactate. Arch Neurol 16, 494496 
Prange J: D- und L-Laktat bei bakterieller Meningitis. Med. Diss. Göttingen 2004

Reiber H (1980): Eine schnelle und einfache nephelometrische Bestimmungsmethode für Protein im Liquor cerebrospinalis. J Clin Chem Clin Biochem 모, 1237

Reiber H, Felgenhauer K (1987): Protein transfer at the blood cerebrospinal fluid barrier and the quantitation of the humoral immune response within the central nervous system. Clin Chim Acta $\underline{163}, 319-328$

Reiber H, Otto M, Trendelenburg C, Wormek A (2001): Reporting cerebrospinal fluid data: knowledge base and interpretation software. Clin Chem Lab Med 푸, 324-332

Reiber H: Liquorräume, Liquorbildung und Liquorfluss. In: Wildemann B, Oschmann P, Reiber H (Hrsg.): Neurologische Labordiagnostik. Georg Thieme Verlag, Stuttgart 2006 a, $3-4$

Reiber H: Methodische Grundlagen der Analytik. In: Wildemann B, Oschmann P, Reiber H (Hrsg.): Neurologische Labordiagnostik. Georg Thieme Verlag, Stuttgart 2006 b, 17-29

Reiber H: Lactat, Glucose; in: Wildemann B, Oschmann P, Reiber H. (Hrsg.): Neurologische Labordiagnostik. Georg Thieme Verlag, Stuttgart 2006 c, 55-58

Reiber H. (2016): Cerebrospinal fluid data compilation and knowledge-based interpretation of bacterial, viral, parasitic, oncological, chronic inflammatory and demyelinating diseases. Diagnostic patterns not to be missed in neurology and psychiatry. Arq Neuropsiquiatr $\underline{74}$, $337-350$

Rosen ST, Aisner J, Makuch RW, et al. (1982): Carcinomatous leptomeningitis in small cell lung cancer: A clinicopathologic review of the National Cancer Institute experience. Medicine $\underline{61}, 45-53$ 
Schabet M, Kloeter I, Adam T, Heidemann E, Wiethölter H (1986): Diagnosis and treatment of meningeal carcinomatosis in ten patients with breast cancer. Eur Neurol 25, 403-411

Siemens Healthcare 2017: Magnetresonanztomographie. Was ist ein MRT? https://www.patienteninfo.siemens.de/untersuchungsmethodenbehandlungsmethoden/bildgebungsverfahren/magnetresonanztomographie (besucht am 21.02.2017)

Staib F, Seibold M, Antweiler E, Zimmer C, Heitz J, Stoltenburg-Didinger G (1990): Cerebrospinal fluid indices in cryptococcal and tuberculous meningitis: the spider web coagulum and its diagnostic significance. Mycoses $\underline{33}, 359-367$

Storch-Hagenlocher B: Liquorpunktion. In: Wildemann B, Oschmann P, Reiber H (Hrsg.): Neurologische Labordiagnostik. Georg Thieme Verlag, Stuttgart 2006 a, 30-34

Storch-Hagenlocher B: Zelldiagnostik. In: Wildemann B, Oschmann P, Reiber H (Hrsg.): Neurologische Labordiagnostik. Georg Thieme Verlag, Stuttgart 2006 b, 35-45

Thwaites GE, Chau TT, Stepniewska K, Phu NH, Chuong LV, Sinh DX, White NJ, Parry CM, Farrar JJ (2002): Diagnosis of adult tuberculous meningitis by use of clinical and laboratory features. Lancet $\underline{360}, 1287-1292$

van Zanten AP, Twijnstra A, Hart AA, Ongerboer de Visser BW (1986): Cerebrospinal fluid lactate dehydrogenase activities in patients with central nervous system metastases. Clin Chim Acta $161,259-268$

Veening JG, Barendregt HP (2010): The regulation of brain states by neuroactive substances distributed via the cerebrospinal fluid; a review. Cerebrospinal Fluid Res $\underline{7}, 1$

Vogt-Schaden M: sekundäre Hirntumoren. In: Wildemann, B, Oschmann P, Reiber H (Hrsg.): Neurologische Labordiagnostik. Georg-Thieme Verlag, Stuttgart 2006, 210-212 
von Wasielewski R, Seth S, Franklin J, Fischer R, Hubner K, Hansmann ML, Diehl V, Georgii A (2000): Tissue eosinophilia correlates strongly with poor prognosis in nodular sclerosing Hodgkin's disease, allowing for known prognostic factors. Blood 모, 1207-1213

Walz W, Mukerji S (1988): Lactate release from cultured astrocytes and neurons: A comparison. Glia $\underline{1}$, 366-370

Wang P, Piao Y, Zhang X, Li W, Hao X (2013): The concentration of CYFRA 21-1, NSE and CEA in cerebro-spinal fluid can be useful indicators for diagnosis of meningeal carcinomatosis of lung cancer. Cancer Biomark $\underline{13}, 123-130$

Wasserstrom WR, Glass JP, Posner JB (1982): Diagnosis and treatment of leptomeningeal metastases from solid tumors: Experience with 90 patients. Cancer $\underline{49}$, 759-772

Wellmer A, Prange J, Gerber J, Zysk G, Lange P, Michel U, Eiffert H, Nau R (2001): D- and L-lactate in rabbit and human bacterial meningitis. Scand. J Infect Dis $\underline{33}$, 909-913

Wurster U: Elektrophorese Verfahren - Nachweis und Bedeutung von oligoklonalen Banden. In: Zettl UK, Lehmitz R, Mix E (Hrsg.): Klinische Labordiagnostik. 2. Auflage; de Gruyter, Berlin 2005, 207-236

Zettl UK, Mix E, Lehmittz R: Neoplastische Erkrankungen des Nervensystems. In: Zettl UK, Lehmnitz R, Mix E (Hrsg.): Klinische Liquordiagnostik, 2. Auflage; de Gruyter, Berlin 2005, 431-439

Zou Y, He J, Guo L, Bu H, Liu Y (2015): Prediction of cerebrospinal fluid parameters for tuberculous meningitis. Diagn Cytopathol 43, 701-704 


\section{Lebenslauf}

Am 05. August 1988 wurde ich als zweites Kind der Eheleute Elisabeth Trimmel, geborene Höller, und Dieter Trimmel in Bremen geboren. Mein Vater ist inzwischen Rentner und arbeitete früher als IT-Spezialist. Meine Mutter arbeitete, bis wir Kinder geboren wurden, als Erzieherin im Kindergarten. Meine ältere Schwester heißt Christina Trimmel und meine jüngere Schwester heißt Sabrina Trimmel.

Von 1995 bis 1999 besuchte ich die Grundschule an der Augsburger Straße in Bremen, danach von 1999 bis 2001 die Orientierungsstufe am Schulzentrum Findorff in Bremen. Anschließend wechselte ich auf das Hermann-Böse-Gymnasium in Bremen, an dem ich im Juni 2008 die allgemeine Hochschulreife erlangte.

Während meiner Schulzeit nahm ich 2006 u. a. an dem Wettbewerb „Forschen in eigener Sache-FIES“ sowie am „Model European Parliament- Baltic Sea Region“ teil. Im Jahr 2007 organisierte ich zusammen mit meinem damaligen Sport-Leistenkurs unter der Leitung von Herrn Michael Jentzsch den „Unicef Spendenlauf“ in Bremen. Mit diesem konnten wir den damaligen nationalen Rekord in Bezug auf die höchste Spendensumme brechen und erhielten für die Organisation außerdem den Bremer Bürgerpreis in der Kategorie „Junior““. Zum Wintersemester 2008 immatrikulierte ich mich an der Georg-August-Universität Göttingen für das Fach Humanmedizin. Im März 2011 legte ich den ersten Abschnitt der Ärztlichen Prüfung ab.

Von September 2011 bis Juni 2015 arbeitete ich als studentische Aushilfe im Bereich Pflege auf der Intensivstation im Evangelischen Krankenhaus Weende. Dort leitete ich die studentischen Pflegekräfte von Januar 2013 bis Mai 2014 als Wachverteiler. Während des Studiums engagierte ich mich als aktiver Helfer für die DKMS-Typisierungsaktion „Torsten will leben!“ im Februar 2013 in Bremen und war ab Oktober 2013 als Semestersprecher tätig. Im März 2014 bestand ich den zweiten Abschnitt der Ärztlichen Prüfung und absolvierte anschließend mein Praktisches Jahr. Das Tertial der Inneren Medizin machte ich im Evangelischen Krankenhaus Weende. Das Chirurgie-Tertial absolvierte ich anschließend am St.John's Medical College in Bangalore, Indien. Als Wahlfach entschied ich mich damals für die Anästhesiologie. Das dazugehörige Tertial leistete ich im Klinikum Bremen-Mitte ab.

Nach dem Bestehen des dritten Abschnittes der Ärztlichen Prüfung im Mai 2015 begann ich meine berufliche Laufbahn als Arzt im August 2015 als Assistenzarzt für Anästhesiologie im Klinikum Bremen-Mitte. 